\title{
Suitport Feasibility - Human Pressurized Space Suit Donning Tests with the Marman Clamp and Pneumatic Flipper Suitport Concepts
}

\author{
Robert M. Boyle ${ }^{1}$, Liana Rodriggs ${ }^{2}$, Charles Allton ${ }^{3}$, Mallory Jennings ${ }^{4}$, Lindsay Aitchison ${ }^{5}$ \\ Lyndon B. Johnson Space Center \\ National Aeronautics and Space Administration \\ Houston, Texas 77058 \\ E-Mail: Robert.m.boyle@nasa.gov; Phone: 281.483.5349
}

\begin{abstract}
The suitport concept has been recently implemented as part of the small pressurized lunar rover (Currently the Space Exploration vehicle, or SEV) and the Multi-Mission Space Exploration Vehicle (MMSEV) concept demonstrator vehicle. Suitport replaces or augments the traditional airlock function of a spacecraft by providing a bulkhead opening, capture mechanism, and sealing system to allow ingress and egress of a space suit while the space suit remains outside of the pressurized volume of the spacecraft. This presents significant new opportunities to EVA exploration in both microgravity and surface environments. The suitport concept will enable three main improvements in EVA by providing reductions in: pre-EVA time from hours to less than thirty minutes; airlock consumables; contamination returned to the cabin with the EVA crewmember. Two second generation suitports were designed and tested. The previously reported second generation Marman Clamp suitport and a newer concept, the Pneumatic Flipper Suitport. These second generation suitports demonstrated human donning and doffing of the $\mathrm{Z1}$ spacesuit with an 8.3 psi pressure differential across the spacesuit. Testing was performed using the JSC B32 Chamber B, a human rated vacuum chamber. The test included human rated suitports, the suitport compatible prototype suit, and chamber modifications. This test brought these three elements together in the first ever pressurized donning of a rear entry suit through a suitport. This paper presents the results of the testing, including unexpected difficulties with doffing, and engineering solutions implemented to ease the difficulties. A review of suitport functions, including a discussion of the need to doff a pressurized suit in earth gravity, is included. Recommendations for future design and testing are documented.
\end{abstract}

\footnotetext{
${ }^{1}$ Crew and Thermal Systems Division, NASA Johnson Space Center, Mail Code: EC5, 2101 NASA Parkway, Houston, TX, 77058

${ }^{2}$ Crew and Thermal Systems Division, NASA Johnson Space Center, Mail Code: EC5, 2101 NASA Parkway, Houston, TX, 77058

${ }^{3}$ Crew and Thermal Systems Division, NASA Johnson Space Center, Mail Code: EC2, 2101 NASA Parkway, Houston, TX, 77058

${ }^{4}$ Crew and Thermal Systems Division, NASA Johnson Space Center, Mail Code: EC5, 2101 NASA Parkway, Houston, TX, 77058

${ }^{5}$ Crew and Thermal Systems Division, NASA Johnson Space Center, Mail Code: EC5, 2101 NASA Parkway, Houston, TX, 77058
} 


\section{Introduction}

Suitport replaces or augments the traditional airlock function of a spacecraft by providing a bulkhead opening, capture mechanism, and sealing system to allow ingress and egress of a spacesuit while the spacesuit remains outside of the pressurized volume of the spacecraft. This presents significant new opportunities to EVA exploration in both microgravity and surface environments.

The suitport concept will enable three main improvements in EVA by providing reductions in: pre-EVA time from hours to less than thirty minutes; airlock consumables; contamination returned to the cabin with the EVA crewmember.

Suitport capitalizes on the atmospheres working group recommendation of an 8 psi and $32 \%$ cabin environment for exploration spacecraft. The reduced cabin pressure allows the suitport and the suit to be exposed to full cabin pressure while maintaining a lightweight, EVA friendly design. Suitport was originally patented in 1989 by M. Cohen. Subsequent development focused on a vehicle and suits designed for hazardous materials work.

In recent years, the suitport has been tested on three variants of the lunar rover and microgravity exploration concept demonstration vehicles at JSC and as part of Desert RATS ${ }^{6}$. This testing has shown true potential to change the way NASA as an agency utilizes Extra-Vehicular Activity (EVA). Where previous testing demonstrated the value of suitport if it was implemented, the goal of the feasibility testing documented here was to increase the Technology Readiness Level (TRL) of suitports.with a true human in the loop test.

To enable a human in the loop feasibility test, the suitport design was updated based on lessons from the first generation suitports, and the goals of the second generation Space Exploration Vehicle (SEV). The intent was to design an integrated vehicle and suitport that would be pressurizable. Both the aft bulkhead of the Multi-Mission Space Exploration Vehicle, MMSEV, and the suitport were designed to accommodate a pressurized vehicle. A second generation suitport emulating a Marman clamp design, and a new design, the Pneumatic Flipper Suitport, were both tested in two series of altitude chamber runs.

\section{Second Generation Suitport Design}

The first generation suitport utilized 4 v-guide clamp bars in a rectangular layout to clamp a Suitport Interface Plate, SIP to a flange on the aft bulkhead of the vehicle. This was meant to emulate the Marman clamps used on circular interfaces, and is thus called a Marman clamp suitport.

The second generation Marman suitport endeavored to reduce the complexity of the suitport mechanism and mechanical overrides. This was done by using two angled Marmon clamp bars instead of the four used on the first generation. Reference Figure 1 for the gen 2 marman clamp suitport. The design of this suitport and the interface to the Z-1 suit has been previously documented. (1)

The Pneumatic Flipper Suitport (PFS) was initiated in response to concerns that the team had limited its focus on the Marman clamp suitport too early. The original down select to the Marman design was influenced by schedule, the need to have suitports complete when the Space Exploration Vehicle cabin was complete, and by the belief that while it might not be ideal, it was a design with a low risk of failure. During the design phase of the second generation Marman suitport, the design team asked to step back and look at other designs. Of particular interest was a passive design, where the Suitport Interface Plate (SIP) would have teeth or curved features that could pass horizontally through a mating frame and then drop vertically down behind teeth on the frame. Once the pressurizable seal was inflated, the suit would be locked in place. A task was

\footnotetext{
${ }^{6}$ Romig, B., Kosmo, J., Gernhardt, M., and Abercromby, A., "Desert Research and Technology Studies 2008 Report," SAE Technical Paper 2009-01-2563, 2009, doi:10.4271/2009-01-2563.
} 
put together to try and make a passive design work, and plywood mockups constructed, but an ergonomically acceptable solution was not found. During these efforts, one of the technicians suggested a re-evaluation of a hinged concept, and subsequently produced a viable low fidelity mock-up. Earlier attempts at emulating a "car door latch" had proved too complicated. This concept used a very simple hinge and spring, and used an airbag to counter-act the spring to open the suitport. Once concept viability was proven with the low fidelity mockup, a mockup suitable for testing with mockup space suits (unpressurized) was assembled. This design showed excellent performance in suitport alignment and human factors.

The Pneumatic Flipper Suitport design combines the alignment and clamp functions into a simple hinged flipper with spring return. Four flippers are arranged to engage the four sides of a rectagular Suitport Interface Plate (SIP) installed on the back of the spacesuit. The wide face of the flipper is angled, and provides an alignment guide for the suitport interface plate as the crewmember backs into the suitport. As the crewmember gets past the hinge point, the flippers rotate perpendicular to the SIP. When the SIP clears the flipper, the flipper is returned to the initial position by the springs. The back of the flipper is shaped to insure SIP retention when pressure is applied. This design allows the suited crewmember to avoid complicated alignment features or procedures, and with minimal training, simply back in until capture is complete. Proximity sensors are installed in the flippers to indicate the flippers have returned to the fully engaged position. The inflatable seal is then pressurized and suitport vestibule pressurization can begin. In order to open the clamps so the crewmember can exit the suitport, the vestibule and pneumatic seals are depressurized, then pressurizable bladders are inflated behind the flippers. These bags force the hinged flippers slightly past the perpendicular position to allow the crewmember to move forward and away from the suitport. In the event of a bag failure, a simple pull cable is routed to each flipper to allow for rapid manual
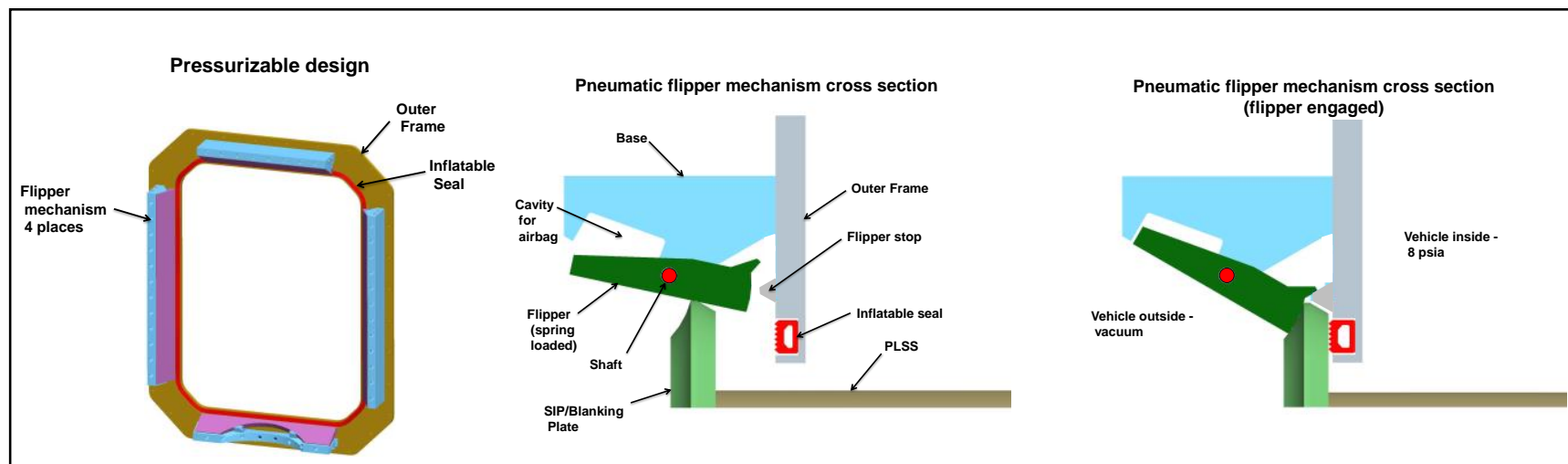

Figure 2. $\quad$ Pneumatic Flipper Suitport Design

egress from the suitport. Reference Figure 2 for detailed crosssections of the pneumatic flipper suitport design.

There were several challenges to implementing the PFS with a spacesuit. It can be noted in figure 2 that the bottom flipper has a wide circular cut-out. This prevents interference with the waist bearing of the suit. Initial prototypes used a passive device for the lower flipper. This design used a cut away flipper. The reduced cross section for the inflatable bag did cause problems with the lower flipper opening in practice.

One desirable feature of the marman clamp design is the load path does not transmit through any active components when pressurized. It simply loads the v-clamps. In the PFS the load path is transmitted through the hinge. In order to make large flippers that would hold the suit within the tolerances required for the inflatable seal to expand across the gap and seal, the hinge bores on the flipper and base had to be extremely well controlledFigure 3 shows details of the base and flipper with the tightly tolerance bore.

The inflatable bags used to open the flippers were constructed of urethane coated nylon, similar to bladder cloth used in the current space suit. Bag construction is shown at the prototype level in figure 4 . The bags were connected by flexible tubing to a chamber provided regulated gas source. After initial construction, the bags in the lower cutaway flipper were oversized to improve the lower flipper opening performance. The remainder of the bags worked acceptably, though testing showed more opening force would be desirable. 
The

contingency

release feature of the PFS was much simpler to operate than the back drive mechanism on the marman clamp suitport. Because the

flippers were simple hinges with spring return, a bicycle cable manual override was constructed. One cable was routed from each of the four flippers to a central point at the top of the suitport. Each cable was attached to a pull fixture, which then attached to a single cable that could be located in proximity to the crewman and provide a simple pull release. For the purposes of this test, the facility provided an arm and a pull mechanism. The manual override worked well enough that for human systems, one could envision spacecraft designers forgoing the complexity and slight consumables of the airbag

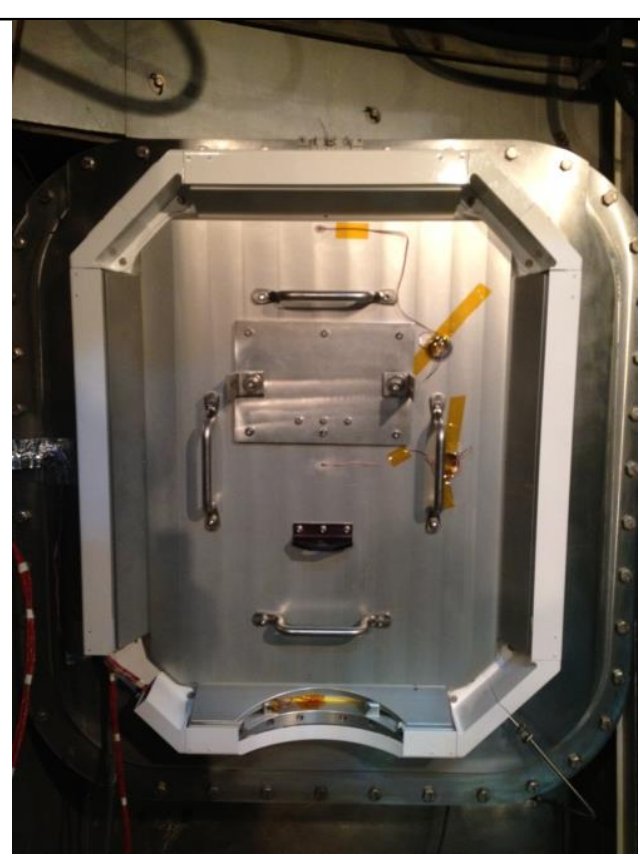

Figure 5. blanking plate installed. system for a dual manual system.

A photograph of the PFS with a blanking plate is shown as figure 5 . A subject in the Z-1 suit using the manual override is presented as figure 6.

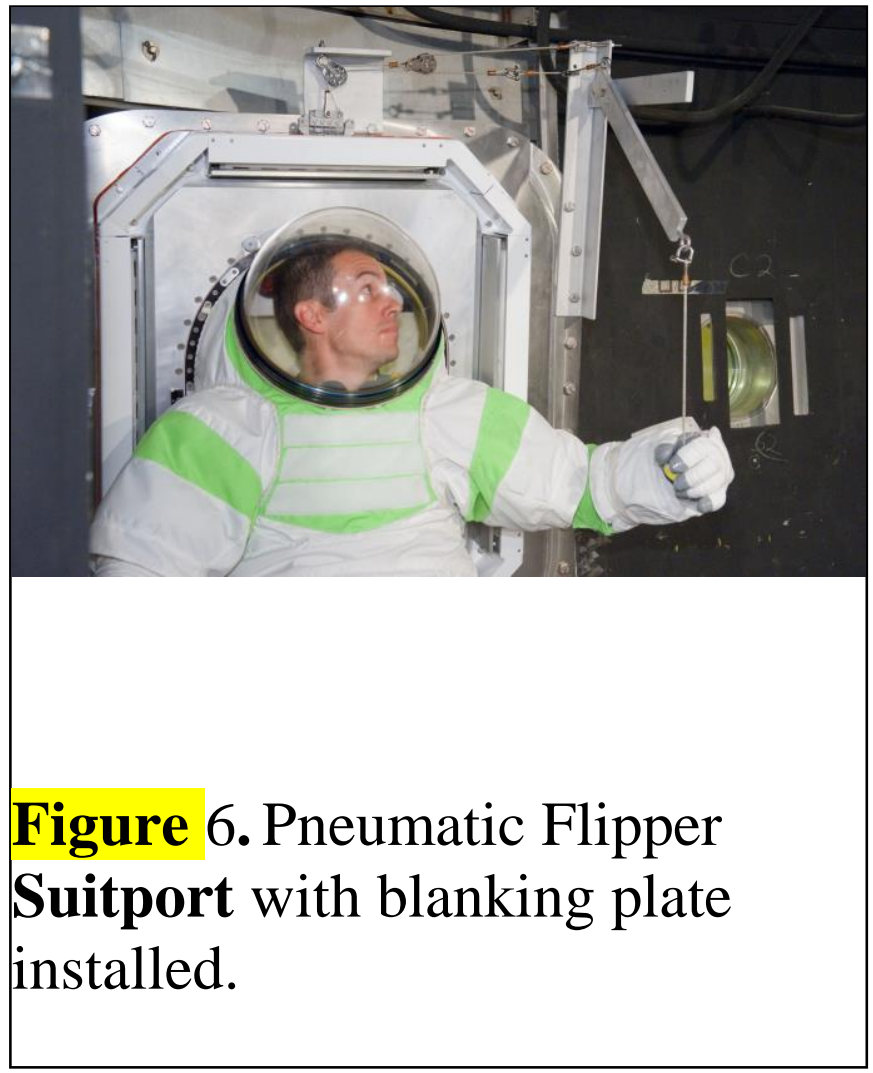




\section{Suit Compatibility with Suitport}

The use of suitports creates several unique challenges for space suit design. Those design challenges, along with work that has been completed to address them, are documented in reference 2. A brief description of the Z-1 suit is provided in the following.

The Z-1 Suit is the first in a series of iteratively developed space suits, referred to as the Z-series. This series of suits is designed to be highly mobile and have the flexibility to adapt to National Aeronautics and Space Administration's (NASA)'s future exploration missions. The Z-1 Suit was developed to be compatible with the second generation suitport, which allows astronauts to connect their suits directly to a vehicle or habitat, as an alternative to the traditional airlock system.

The prototype Z-1 Suit is commonly described as a "soft" planetary exploration suit. The "soft' descriptor is a bit of a misnomer because the suit actually contains several hard mobility elements; the term 'soft' is intended to convey the idea that the primary structures of the suit are pliable fabrics when unpressurized. The Z-1 Suit consists of a soft upper torso, soft lower torso, glove assembly, boot assembly and hemispherical dome helmet.

The Z-1 Suit has bearings in the following locations: 3-bearing shoulder (scye, mid-shoulder, upper arm), wrist, waist, hip, thigh, and ankle, and employs several soft mobility elements to allow for pressurized mobility. The bearings in the suit are custom made for space suit applications by Air-Lock, Inc, and are encased in housings that allow them to be incorporated into the suit via flange mountings.

The Z-1 employs use of a rear-entry door for donning and doffing as well as a Generation 2A Suitport linterface Plate (SIP) for mating with the Generation 2A Marman Clamp Suitport. The Z-1 Suit weighs 126 lbs, however, when including additional test support hardware for this test [SIP (28 lbs), Chamber B Portable Life Support System (PLSS) mock-up (8 lbs)] the total on-back mass when wearing the Z-1 is $162 \mathrm{lbs}$.

The Z-1 was pressurized to 6.0 psid during the Chamber B test dry runs, and 8.3 psid during the manned altitude runs. The test subjects received breathing air and cooling water through a ground support umbilical which was located inside the vestibule, attached at one end to the back of the suit and at the other end to the inside of the utilities feed-through plate. The umbilical was suspended from a retraction system, which allowed it to be pulled into the chamber when the subject was undocked from the suitport and then retract back into the vestibule for docking.

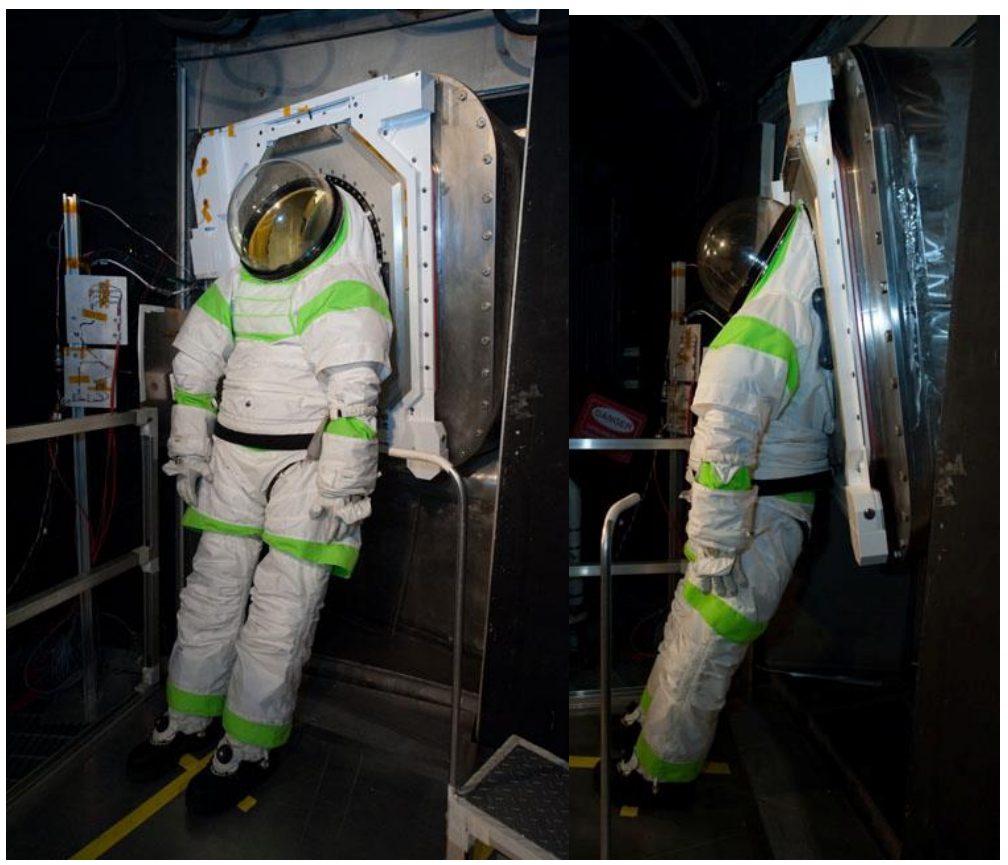

Figure 7 Z-1 Space Suit Assembly Mated to the Marman Suitport in Chamber B 


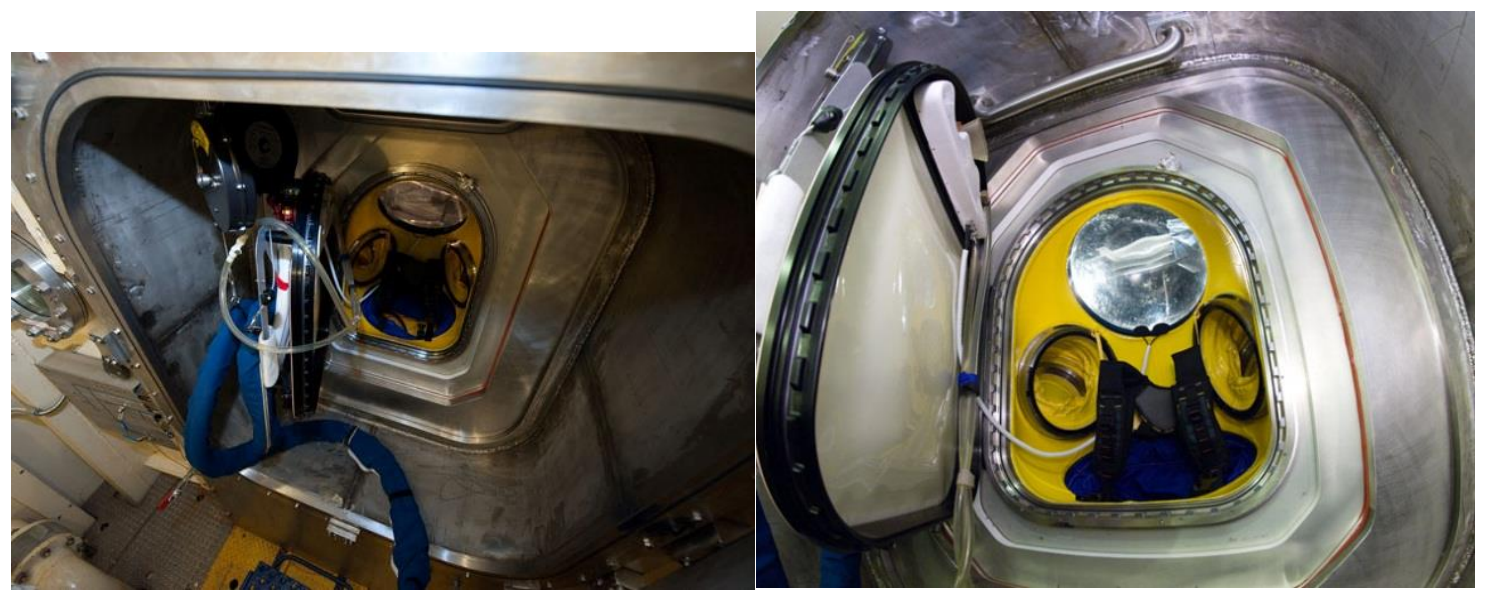

Figure 8 Z-1 Suit Hatch Opening into Chamber B Manlock 2

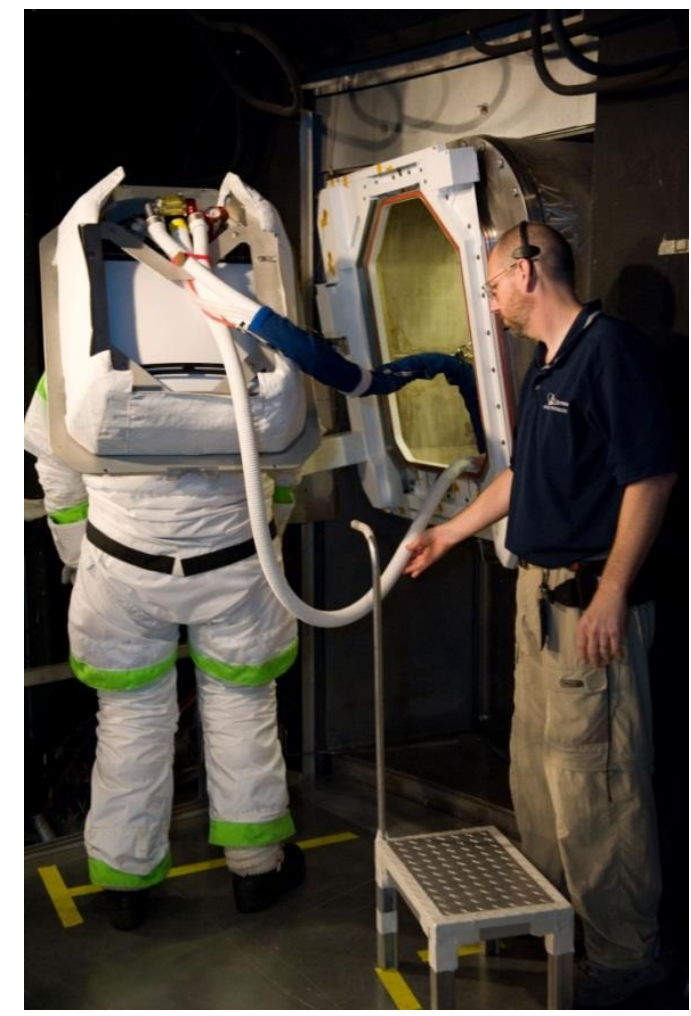

Figure 9 PLSS Mockup and Suit Services Line

\section{Suit Testing}

The first test performed with the Z1 suit and the suitport was a pressurized evaluation on the aft deck of the generation 2A MMSEV. Three AES projects were involved in the evaluations, these included the Suitport project, the Advance Extravehicular Mobility Unit (AEMU) suit project, and the Multi-Mission Space Exploration Vehicle (MMSEV) project. Each team was able to use the evaluation to study a different aspect of the suit-vehicle relationship. The main components evaluated were; 
- Field of view and general use of the suit from the aft deck of the MMSEV.

- Control display- which will allow the astronaut to monitor and actuate their suitport outside the vehicle

- Suit recharge umbilical- which the crew member will attach to their suit after an Extravehicular Activity (EVA) to recharge the oxygen, water, and battery power in the Portable Life Support System (PLSS)

- Manual override system for the marman clamp suitport- which allows the astronaut to get out or back into the vehicle in the case of a system power failure (or other equivalent level of failure) This is currently implemented on the Cabin 2A vehicle and chamber suitport, with a working system.

- Manual override controls for the Pneumatic Flipper Suitport design

- Manual override controls for the vestibule and seal pressurization system

- A secondary objective to investigate jet pack placement for microgravity use of an operational version of a miniaturized Manned Manuevering Unit was also conducted.

The insistence on looking at manual override or backup systems was driven by the need to be able to exit a disabled vehicle through the suitport.

The integrated vehicle, suitport, and Z1 suit testing was the first pressurized suit port alignment and docking test ever performed. This testing confirmed results from the unpressurized mock up suit testing, that the suitport with a nose alignment guide was relatively easy to align and attach. This test also confirmed the usefulness of alignment marks for suitport ingress. This test was somewhat conservative, as the test did not include a beveled PLSS mockup, useful for initial alignment.

This testing identified an interference between the suit hinge and the suitport frame, as well as an issue with the crewmember's heels coming off of the platform. Both issues were noted and addressed prior to the manned pressurized chamber testing. Also observed by the test team and a couple of the test subjects, a large mirror would be useful on the back wall of the aft deck (opposite of the test subject) to assist the test subject with many different tasks.

All other objectives were either completed successfully or a path forward for successful implementation was envisioned. Figures 10, 11, and 12 depict the testing with the Cabin 2A aft deck.

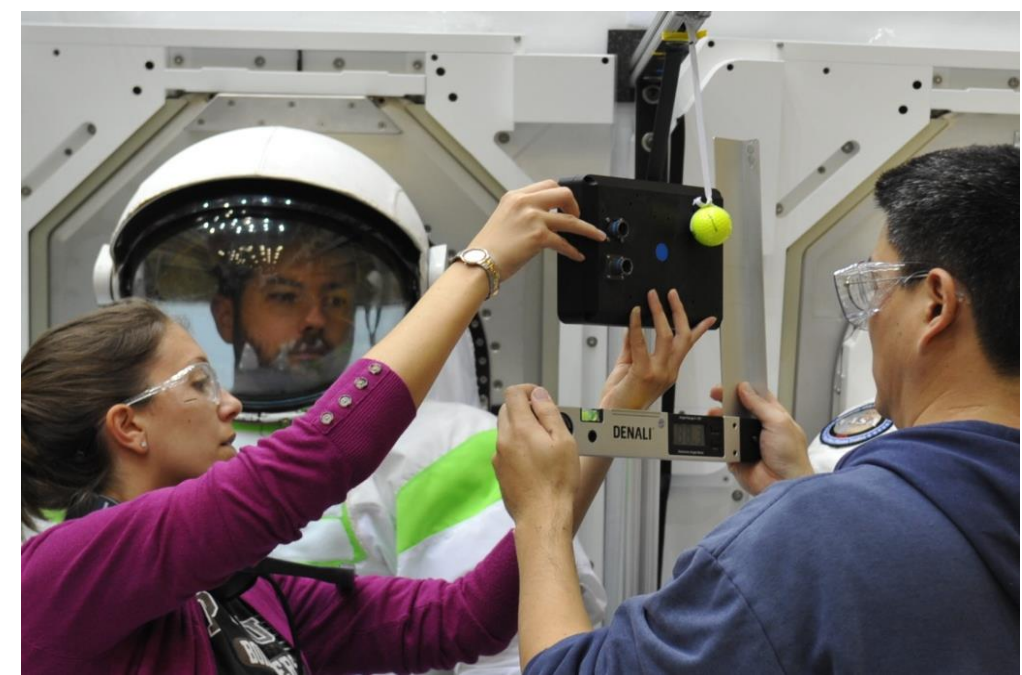

Figure 10: The Test Team holds the display in the Upper Mounting Location and Measures the Relative Location on the Cabin 2A Aft Deck 


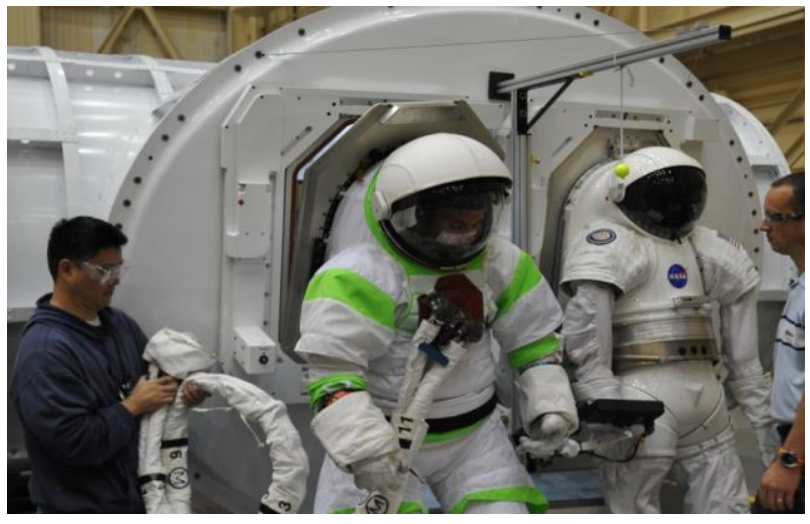

Figure 11: Test Subject Egresses Suitport after Attaching Umbilical from Port Side Location

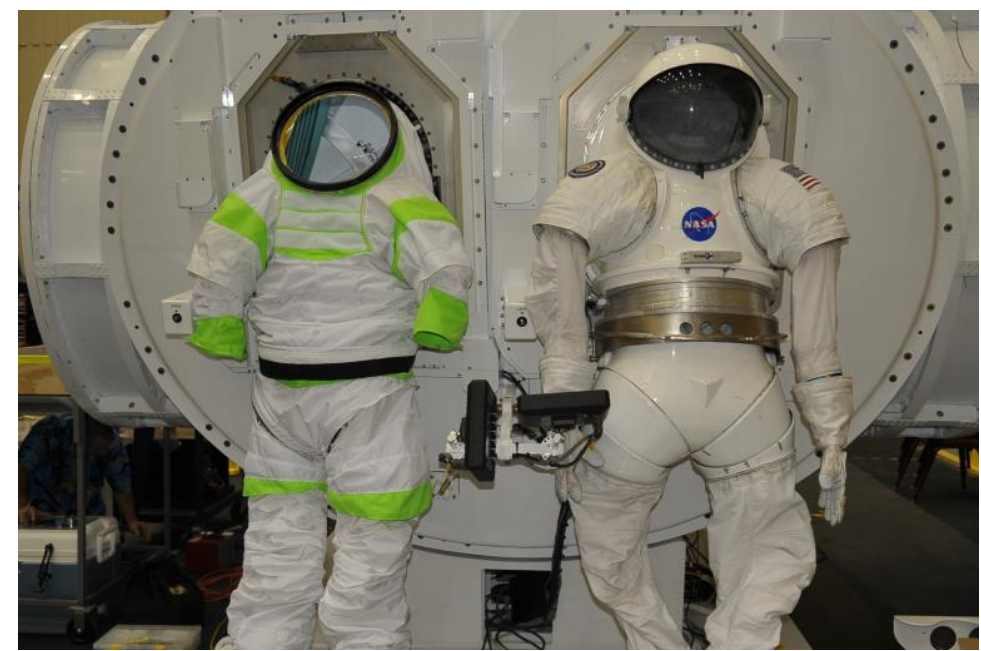

Figure 12: The Z-1 and Mark III Mockup Suits on the MMSEV Cabin prior to Test V Chamber layout and systems

The chamber layout was designed to allow the main portion of the chamber to be depressed to 6.4 psia with a suit installed in the bulkhead fixture while the manlock remained at 14.7. This results in an 8.3 psi delta across the suit for crewmember donning and doffing purposes. To disconnect the suit from the suitport, the suit hatch would be closed, then the vestibule door would be sealed, and the vestibule depressed to chamber pressure. Ventilation and cooling water are provided to the crewmember by an unbilical attached to the suit rear hatch. The chamber layout is shown in figure 13 


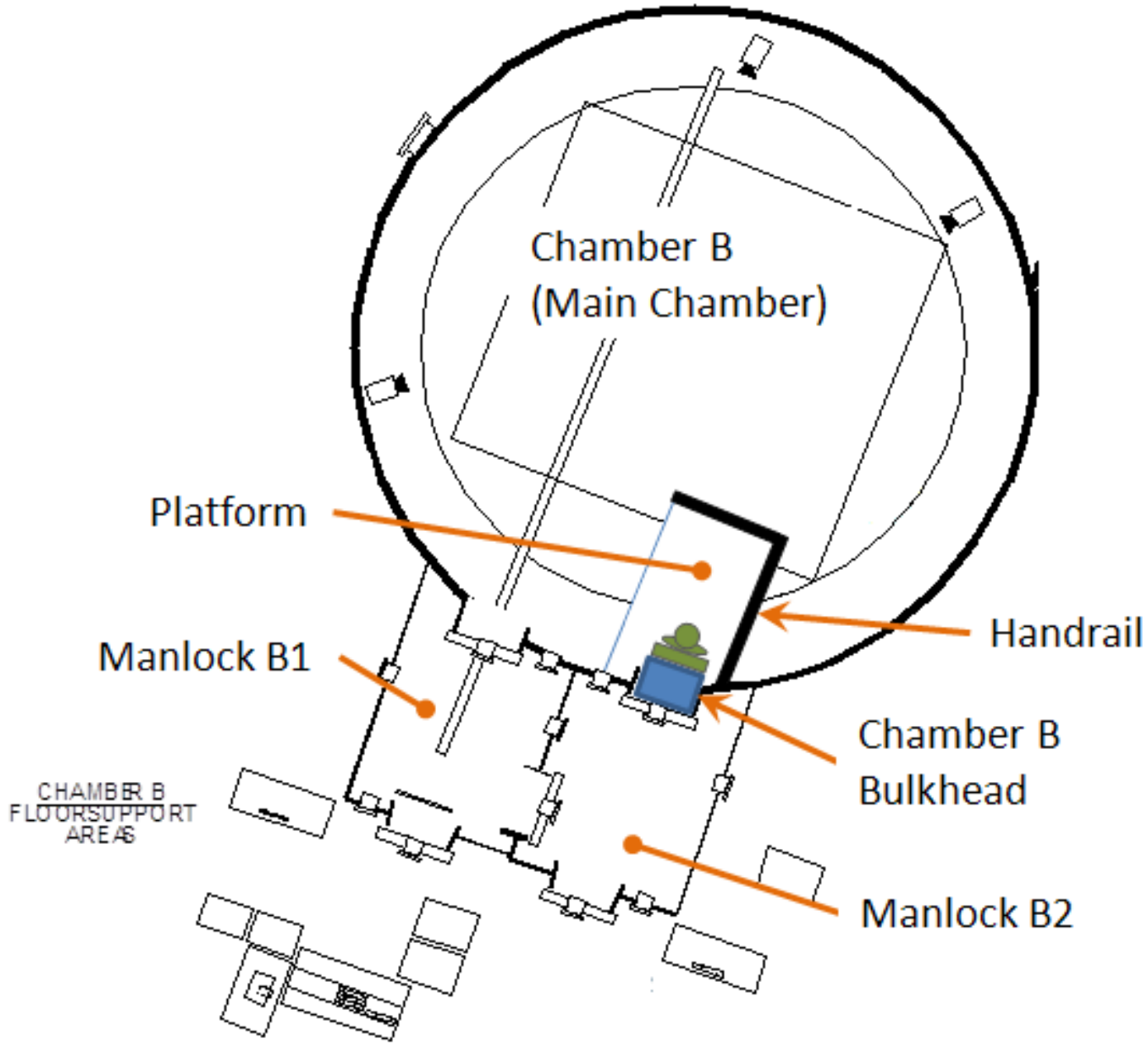

Figure 13 Manned Marman Clamp Suitport Test Chamber B Layout

The Chamber B Bulkhead designed and procured by the Systems Test Branch (EC4) provides an interface to Chamber B for the various suitport designs and the utilities used by the Z-1 suit and suitport.

The Chamber B Bulkhead consisted of four pieces of major hardware: the bulkhead plate, the vestibule, the universal plate, and the vestibule door. The bulkhead plate provides the interface between the manlock-to-main chamber door opening and the vestibule tunnel. See Figure 14. The vestibule provides the interface for the universal plate and minimizes the amount of volume that needs to be repressed and depressed during both manned and unmanned operation. The universal plate interfaces with the suitport mechanism and allows testing of different suitport designs without affecting the bulkhead plate and vestibule tunnel. The vestibule door seals the vestibule and provides the interface for which all suit related services pass through during manned testing. See Figure 15. 


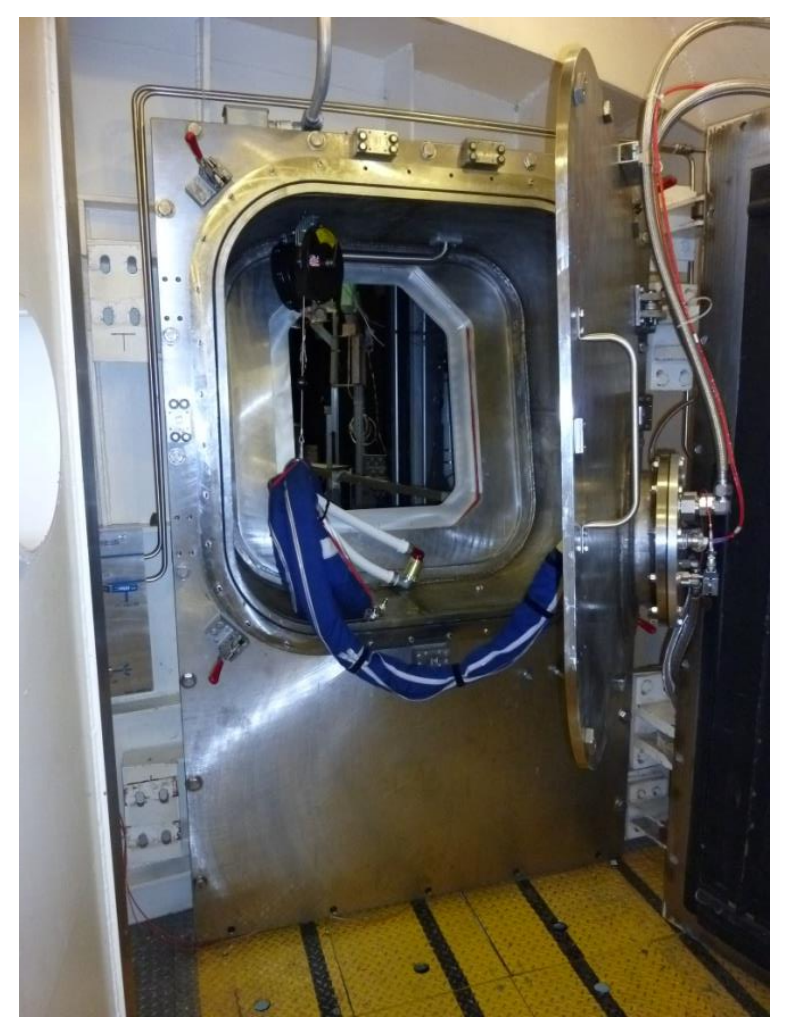

Figure 14 Chamber B Bulkhead

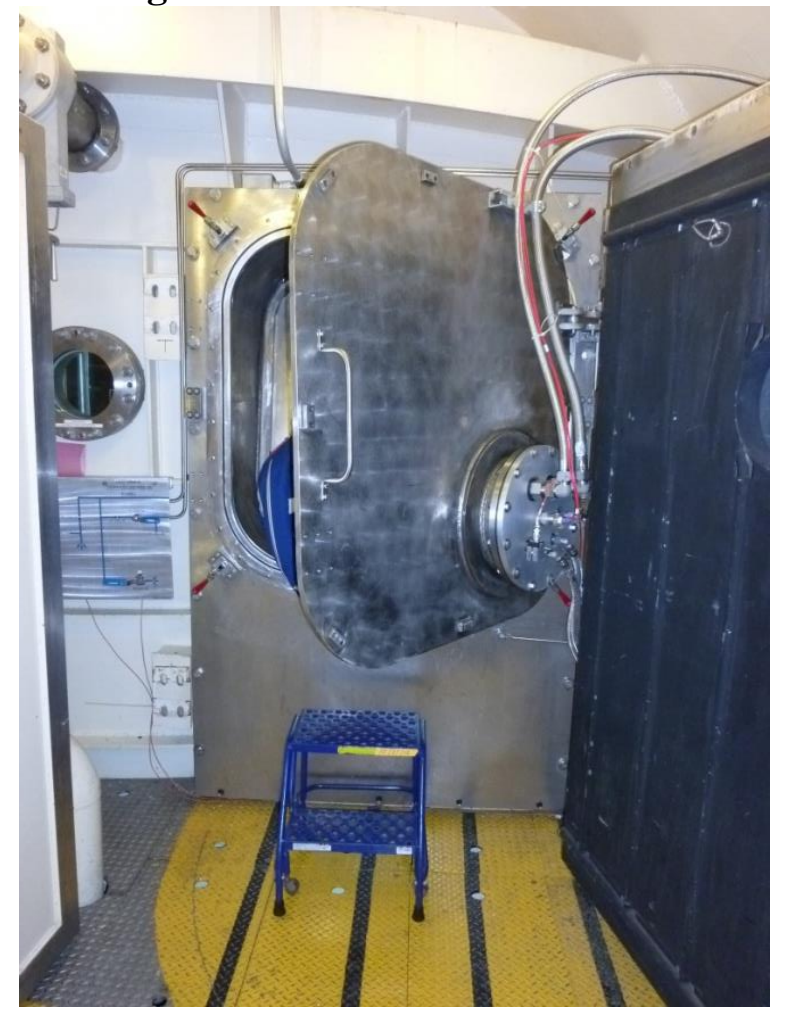

Handrail

Figure 15 Chamber B Bulkhead Vestibule Door 
EC4 installed a handrail for the manned portion of the suitport test. The handrail provides test subject support while they perform suit operations. See Figure 16 for a view of the test area inside the chamber.

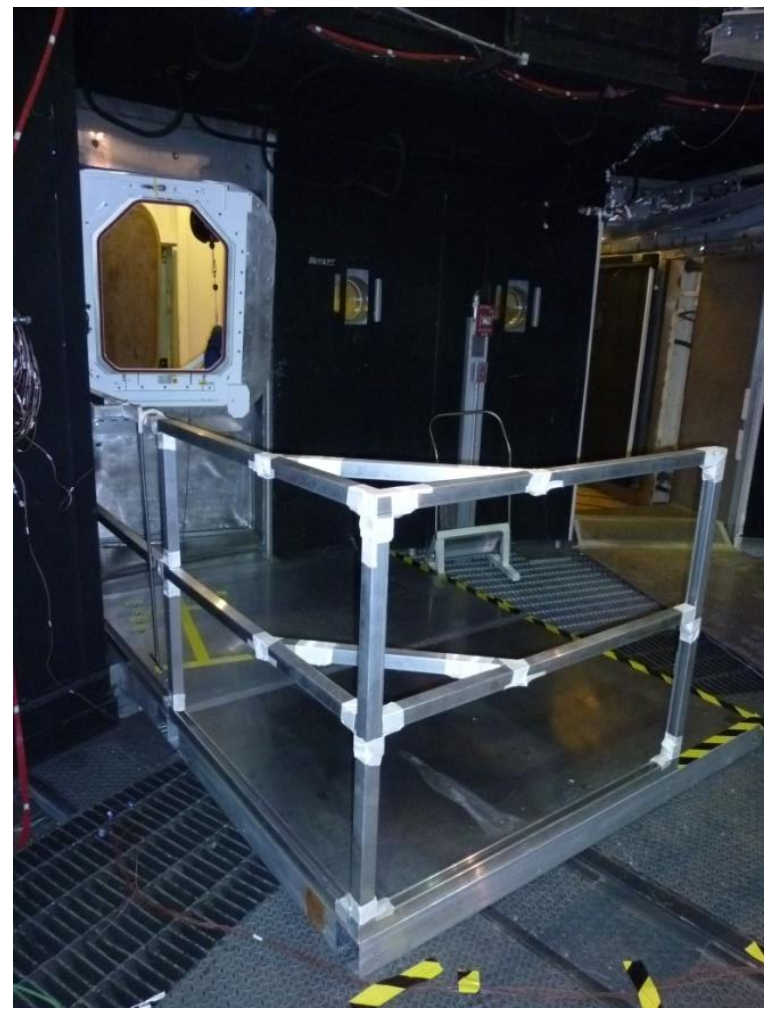

Figure 16 Chamber accommodations: handrail, platform, and suitport

\section{Test Results}

Manned testing was performed in the Crew and Thermal Systems Division (CTSD) Vacuum Chamber B beginning on July 10, 2012 and concluding on July 23, 2012 with the intent of evaluating the Generation 2A Marman Clamp Suitport and Z-1 Prototype Exploration Space Suit Assembly (SSA) in a reduced pressure environment with an 8.3 psi pressure differential across the Suitport and Z-1 suit. Testing was repeated starting on September 18, 2012 and ending on September 28, 2012 with the Pneumatic Flipper Suitport and enhanced donning/doffing aids. The testing fell under the Advanced Exploration Systems (AES) Suitport Project; however, was essentially a joint effort between the Suitport Team, the AES AEMU Advanced Space Suit Assembly Team, and the Systems Test Branch.

A total of five subjects ( 3 engineering and 2 crew) were used in this evaluation. Subjects were asked to provide subjective ratings on the Modified Cooper Harper and Likert Acceptability Scales as they completed the various tasks. They were also asked to provide subjective comments on the tasks. The results and discussion are broken down between the Marman Clamp Suitport and the Z-1 suit.

The test flow followed table 1 . 


\begin{tabular}{|l|}
\hline Suitport Manned Run \\
\hline Depress Main Chamber to 6.4 psia \\
\hline Suitport inflatable seal pressurized to 26.5 psia \\
\hline Vestibule equalized with manlock pressure \\
\hline Suitport inflatable seal pressurized to 34.7 psia \\
\hline Isolate vestibule from manlock \\
\hline Open Vestibule Door \\
\hline Set blower for breathing air to 2 to 3 acfm. \\
\hline Unlock and Open suit hatch \\
\hline Connect LCG \\
\hline Don Suit \\
\hline Set cooling as needed \\
\hline Close and lock suit hatch \\
\hline Set blower to breathing air to 5 to 8 acfm \\
\hline Install PLSS mockup \\
\hline Close vestibule door \\
\hline Equalize vestibule with main chamber \\
\hline Vent suitport inflatable seals to main chamber \\
\hline Suitport marman clamps cycles to open position \\
\hline Test Subject undocks form suitport \\
\hline
\end{tabular}

\begin{tabular}{|l|}
\hline Pressurized Evaluation 1 \\
\hline Perform suit operations \\
\hline Test subject docks to suitport \\
\hline Suitport marman clamps cycles to closed position \\
\hline Repeat as desired \\
\hline Perform suit operations \\
\hline Test subject docks to suitport \\
\hline Suitport marman clamps cycles to closed position \\
\hline Isolate vestibule from manlock \\
\hline Pressurize suitport inflatable seal to 34.7 psia \\
\hline Equalize vestibule pressure with ambient pressure \\
\hline Open vestibule door \\
\hline Remove PLSS mockup \\
\hline Set blower for breathing air to 2 to 3 acfm \\
\hline Open Hatch \\
\hline Pressurized Suit Doffing \\
\hline Doff suit \\
\hline Disconnect LCG \\
\hline Test subject exit vestibule \\
\hline Set blower for breathing air to off \\
\hline Main chamber equalized with ambient pressure \\
\hline Suitport inflatable seal vented to ambient pressure \\
\hline
\end{tabular}

Table 1 - Suitport Chamber Flow

\section{Donning}

The first step for performing the Z-1 suit tasks was to don the suit that was secured to the Suitport. The test subjects did not have any comments concerning suitport affecting the donning of the Z-1 suit.

This test marked the first pressurized donning of a space suit. Out of the five test subjects, three subjects performed one pressurized suit donning each, and two subjects performed three pressurized suit donning each. A series of images demonstrating the pressurized suit donning sequence can be seen below in Figure 17.

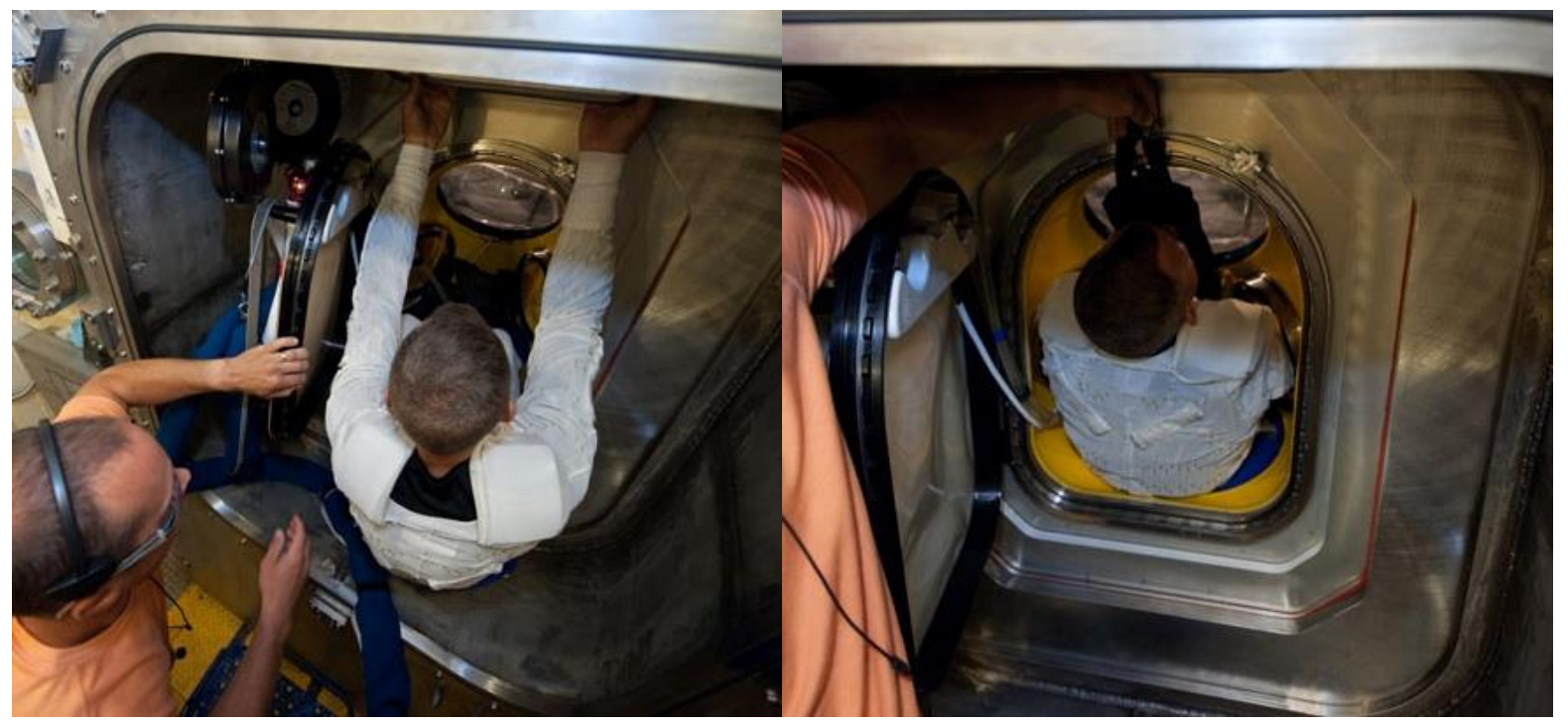




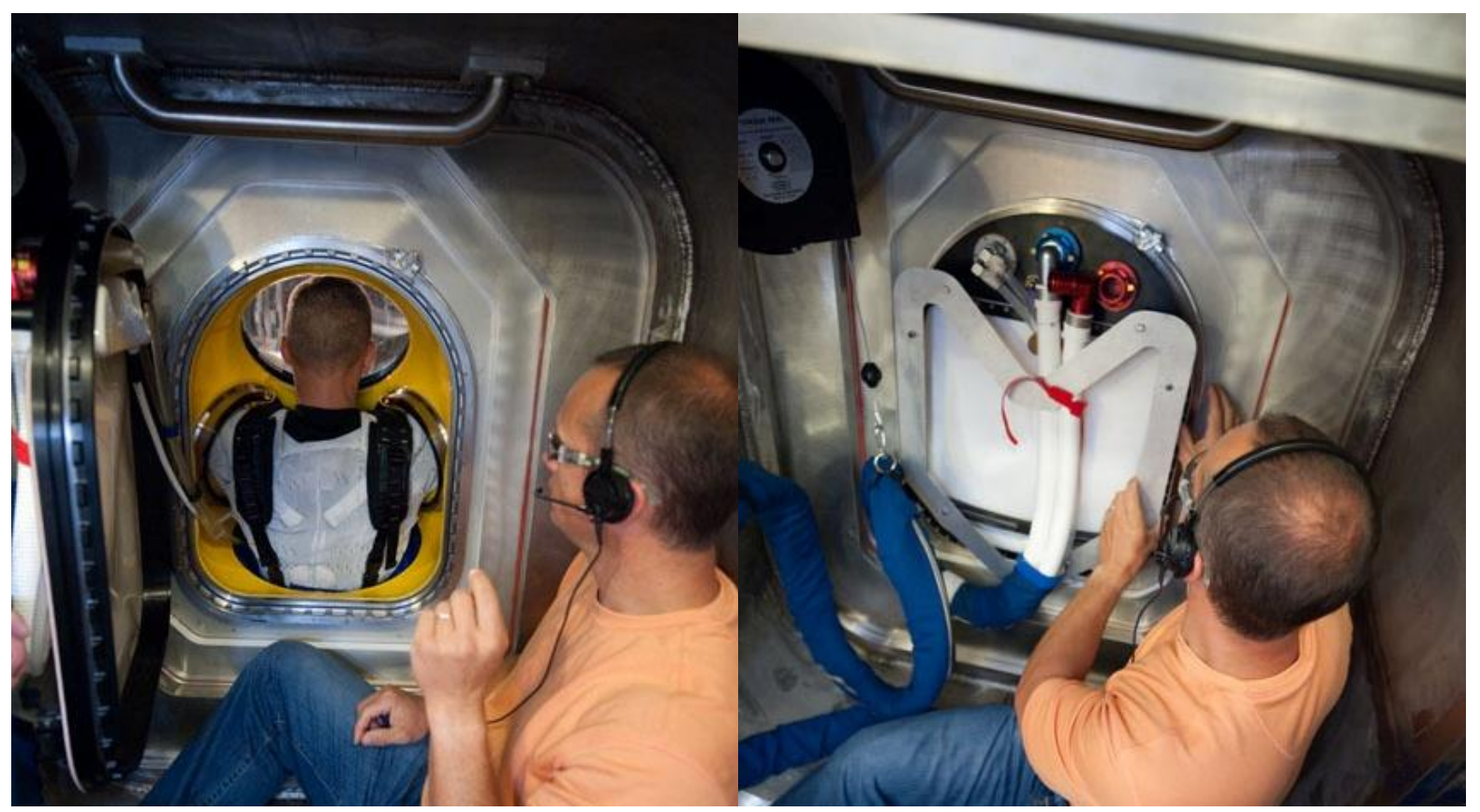

Figure 17 Z-1 Pressurized Donning Sequence

Upon completing donning, subjects were asked to rate their overall ability to don the suit using the Modified Cooper-Harper Scale, which ranks the ability to perform tasks from excellent to containing major deficiencies. The scale is provided below as Table 2 .

Table 2 Modified Cooper Harper Scale

\begin{tabular}{|l|l|}
\hline $\mathbf{1}$ & $\begin{array}{c}\text { Excellent - Highly Desirable; Operator compensation minimal and desired } \\
\text { performance is easily attainable. }\end{array}$ \\
\hline $\mathbf{2}$ & $\begin{array}{c}\text { Good - Negligible Deficiencies; Operator compensation low and desired } \\
\text { performance is attainable. }\end{array}$ \\
\hline $\mathbf{3}$ & $\begin{array}{c}\text { Fair - Some Mildly Unpleasant Deficiencies; Acceptable operator compensation is } \\
\text { required to attain adequate performance. }\end{array}$ \\
\hline $\mathbf{4}$ & $\begin{array}{c}\text { Minor But Annoying Difficulty; Moderately high operator compensation required to } \\
\text { attain adequate performance. }\end{array}$ \\
\hline $\mathbf{5}$ & $\begin{array}{c}\text { Moderately Objectionable Difficulty; High operator compensation required to attain } \\
\text { adequate performance. }\end{array}$ \\
\hline $\mathbf{6}$ & $\begin{array}{c}\text { Very Objectionable Difficulty; Maximum operator compensation required to attain } \\
\text { adequate performance. }\end{array}$ \\
\hline $\mathbf{7}$ & $\begin{array}{c}\text { Major Deficiencies; Maximum operator compensation needed to accomplish tasks } \\
\text { with moderate errors. }\end{array}$ \\
\hline $\mathbf{8}$ & \begin{tabular}{c} 
Major deficiencies; Maximum operator compensation needed to accomplish tasks to \\
\hline
\end{tabular} \\
\hline
\end{tabular}




\begin{tabular}{|l|l|}
\hline & avoid numerous errors. \\
\hline $\mathbf{9}$ & $\begin{array}{c}\text { Major deficiencies; Intense operator compensation needed to accomplish tasks, } \\
\text { frequent errors. }\end{array}$ \\
\hline $\mathbf{1 0}$ & Major deficiencies; Unable to perform task. \\
\hline
\end{tabular}

The subjects' ratings are provided in Figure 18. For subjects who donned the suit multiple times, the rating shown is the average value of the response.

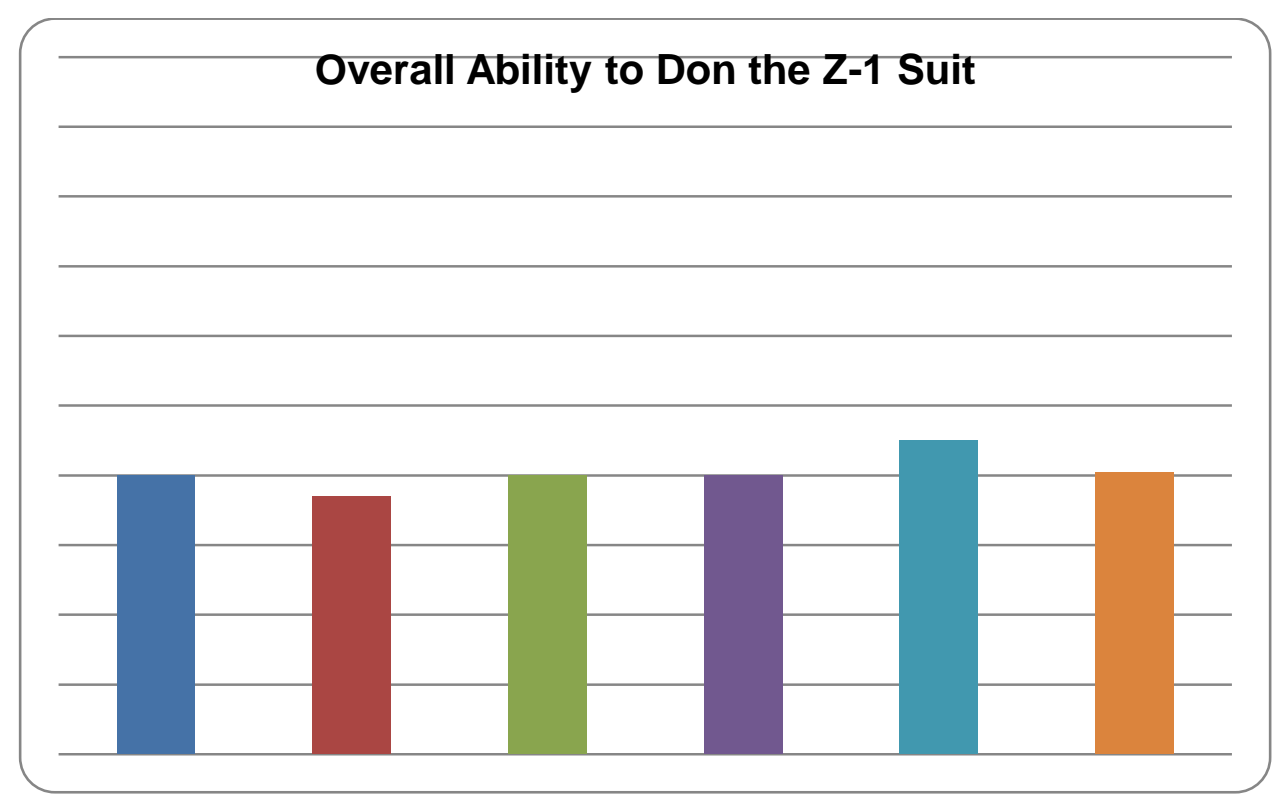

Figure 18 Suit Donning Ratings on the Modified Cooper-Harper Scale

As shown in Figure 18, all five subjects provided very similar ratings for pressurized suit donning. The average rating of ' 4 ' indicates that subjects encountered minor but annoying difficulties while donning the suit, and had to compensate to adequately complete the task.

Two subjects were unable to don the suit on their first donning attempt. Through discussion with and observation of the subjects during their failed donning attempts, it was discovered that the subjects failed to don the suit because they were unable to work their foot around the knee break of the suit. The Z-1 suit tends to have a natural break in the knee when pressurized.

The break in the suit knees creates an edge that all subjects had to work their feet past in order to get down into the boots. Due to the set leg diameter, the subjects had a given amount of space to work their foot past. The two subjects who failed to don on the first attempt commented that there was not enough room to work their foot around the knee break and then past the shin, and that they became hung up at one place or the other. While this issue kept only two subjects from being able to don on the first attempt, all subjects noticed this issue and had to exert some effort to get past the knee break and down into the boots.

It is not completely clear why some subjects were successful while others were not. It is likely due to the combination of subject leg anthropometry and suit geometry. For the two subjects who failed to don the suit on the first attempt, the chamber was repressurized and the suit legs were propped up on the metal doffing step, which had been designed to be used as a suit doffing aid. The chamber was then depressurized and the subjects attempted to don the suit once more. This modified donning configuration can be seen in the Figure 19. 


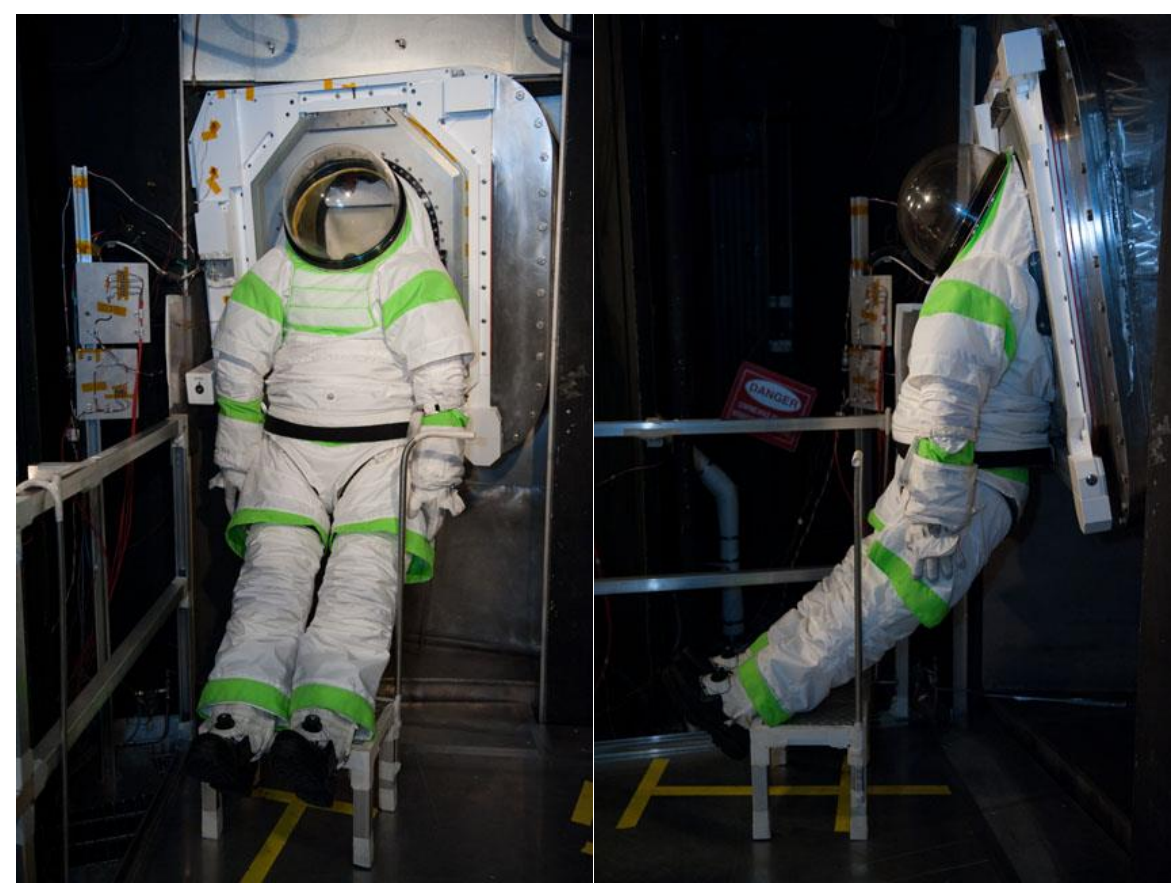

Figure 19 Modified Z-1 Suit Donning Configuration

As seen in Figure 19, the doffing aid step helped to hold the suit legs straight, reducing the bend at the knees. Both subjects who failed to don on their first attempt with the boots flat on the floor were successful at donning the suit in this modified configuration. It seemed that there was a clearer donning path in the lower torso using this modified configuration.

When asked about interferences encountered while donning the suit, all subjects commented on the knee break. Multiple subjects also cited trouble working their arms past the shoulders when donning the suit. It is believed the manner in which the bladder folded in between the scye and mid-shoulder bearings of the suit, in combination with the fixed location of the scye and mid-shoulder bearings, created a limited window for the subjects to work their arms past. Each subject had to essentially develop his own technique for working his arms into the suit. Subjects tried inserting one arm at a time as well as sliding both arms in at once. The latter technique seemed to work the best. Bunching in the underarm area can be reduced in unpressurized donning scenarios by holding the lower arms fully extended during donning; that approach had no effect on the delta pressure donning scenarios.

Another issue noted by subjects during suit donning was the ability of the lower leg and boot components to freely rotate, and at times spin up to 180 degrees so that the components were facing the direction opposite the upper torso. Since there are not stops on the hip or ankle bearings, the bearings tended to rotate as the subjects worked their way into the suit. This issue did not prevent any subjects from donning, as they were able to kick and spin the boots/legs back into the correct configuration, but it was a nuisance.

\section{Undocking}

The test subject undocked from the suitport as part of the test procedures. The test team asked about two areas of interest concerning the undocking from the suitport.

The first area of interest is the time involved in cycling the Marman clamps from the closed to open position. The test subjects indicated that the time for cycling the Marman clamps needed to be shorter. In addition, test subjects indicated that the need to push the SIP against the suitport during the cycling of the Marman clamp is a task they would rather not perform. A test subject did indicate that the noise from the Marman clamp cycling is a feedback they like since the noise allowed them to know when the clamps started and stopped. From conversations with experienced EVA crewmembers, it is likely this sound will be conducted into the spacesuit in real vacuum use. 
The test subjects indicated that undocking from the suitport is a very easy. Depending on the test subject, some indicated they would prefer more feedback while others indicated that they have plenty of feedback.

\section{Docking}

The test subjects docked to the suitport after performing pressurized operations as part of the test procedures. The test team asked about four specific areas related to docking.

The first area concerned the use of the Nose Alignment Guide (NAG). The NAG is on the lower edge of the SIP and is intended to aid in properly aligning the SIP into the suitport when docking. All the test subjects responded that they did not feel the NAG during docking but observation of the docking showed that the NAG performed the intended function of acting as a both a guide and a stop for docking.

The second area addressed the usefulness of the PLSS mockup to aid in the alignment of the suit to the suitport during docking. The majority of the test subjects indicated that the PLSS performed as intended. The test subjects all responded that they used the PLSS as a guide to aid in docking.

The third area concerned the time required to cycle the Marman clamps from the open to closed position. As with the undocking, the test subjects all commented that the time should be shorter. Again as with undocking, pushing the interface plate against the suitport during the cycling of the Marman clamp is a task they would rather not perform. One subject indicated that pushing the SIP would be difficult especially after an Extravehicular Activity (EVA) due to fatigue. As with the undocking, a test subject did indicate that the noise from the Marman clamp cycling is a feedback they like since the noise allowed them to know when the clamps started and stopped.

The last area addressed the more general question of the ability of the test subjects to dock with the suitport. Test subjects indicated that the training received during their dry runs was very helpful and that the alignment mark on the platform was helpful in orientation of the Z-1 suit with respect to the suitport.

\section{Doffing}

After completing the suitport operations, the last step for the subjects was doffing the Z-1 suit. The subjects were asked to give feedback on the use of the pull-up bar for doffing. The pull-up bar was mounted to the top inside of the vestibule. The test subjects all indicated that the existing pull-up bar is helpful in doffing the suit but that another pull up bar located farther from the suit would be helpful. Alternatively, the test subjects also indicated that a dip bar would help in doffing.

In addition to the first pressurized suit donning, this test also marked the first pressurized doffing of a space suit. Doffing the pressurized suit proved to be more difficult than anticipated. Out of the five test subjects, only two test subjects were able to successfully doff the pressurized Z-1 suit. Both of these subjects were able to complete three pressurized doffing trials. A series of images demonstrating the pressurized suit doffing sequence can be seen below in Figure 20. 


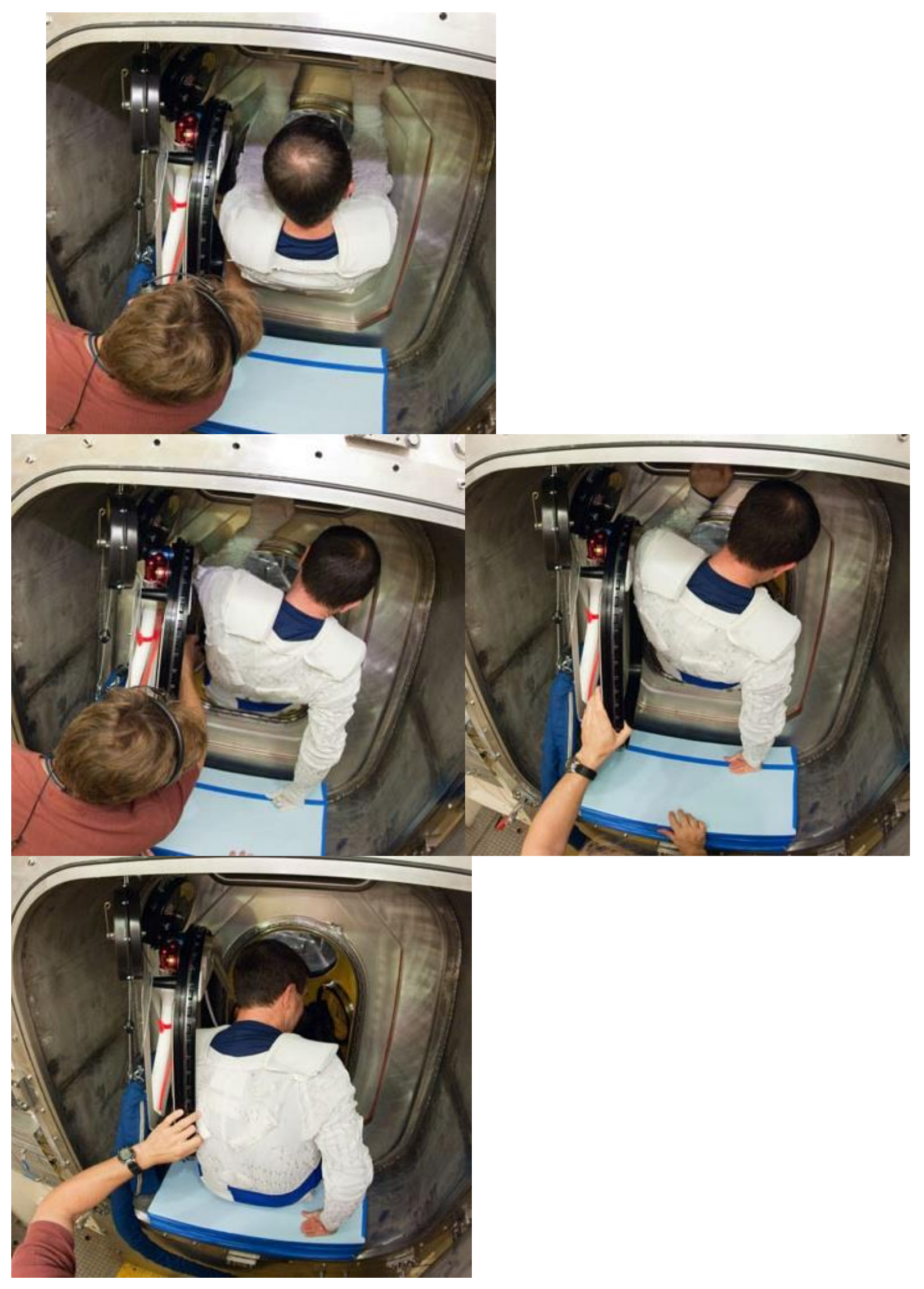


Figure 20 Z-1 Pressurized Doffing Sequence

As with suit donning, subjects were asked to rate their overall ability to doff the suit using the Modified CooperHarper Scale. Each subject's rating as well as the average rating for the doffing task is provided below. For the two subjects who doffed the suit multiple times, their average rating is what is shown in Figure 21.

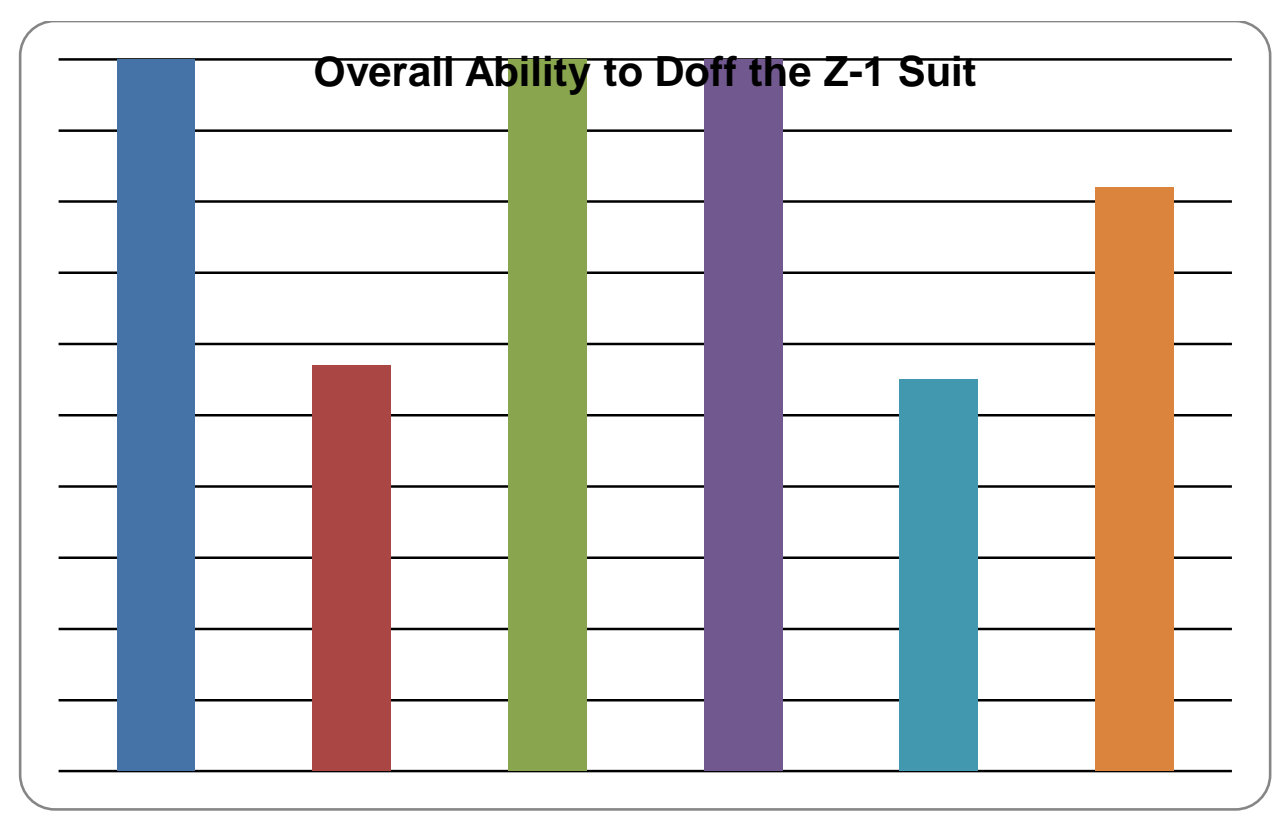

Figure 21 Suit Doffing Ratings on the Modified Cooper-Harper Scale

The three subjects who were unable to doff the suit rated doffing as a '10 - Major deficiencies; unable to perform task'. The subjects who were able to complete the task had average ratings between ' 5 ' and ' 6 ', indicating that the task was moderately to very objectionable. There were several factors which potentially contributed to the suit doffing issues and which will be discussed below.

The first subject to attempt pressurized doffing felt that his left foot was becoming stuck on a protruding bladder fold just above the boot, and he was unable to work his foot past this fold, and thus get it out of the boot. The Z-1 Suit has $31 / 2$ inches of sizing in the lower leg, which is let out/taken up by adjusting the loop on the axial restraint. Since this sizing method essentially involves cinching down the restraint/bladder for smaller subjects, the suit has 3 $1 / 2$ inches of restraint and bladder material at the lower leg to boot interface when the suit is sized in its smallest leg configurations. Such was the case for test subject 1, creating the potential for a large bladder fold inside the suit.

Following the first test day, a new procedure was put in place to manipulate the lower leg bladder prior to closing up and pumping down the chamber. It is believed that this procedure was able to successfully minimize the bladder folds at the ankle because no other subjects reported insurmountable interference at that location; however, this procedural change did not remedy all pressurized doffing issues.

The other two subjects that failed to doff the suit reported different issues. Both subject 3 and subject 4 encountered two primary interference points during doffing. The suit knee tended to bend as the subjects attempted to pull their feet out of the suit, creating a hard edge at the back of the knees. To try to work past this edge, subjects attempted to force their legs straight, but the result was that the top of their feet became caught on the bladder break at the ankle joint, and they could not get their feet out of the boots. The combination of the knee and ankle break caught the subjects in the suit lower torso. One subject had trouble getting his glutes over the ledge at the bottom of the suit hatch opening. He felt that he needed something more than the single pull-up bar to provide him with more leverage to pull himself out of the suit.

As noted in the Modified Cooper-Harper Ratings above, suit doffing was not easy for the two subjects who were successful. Subject 2 doffed the pressurized suit three times. On his first and third trial, he began with the suit 
boots flat on the floor, and on his second trial, he used the doff aid. He commented that the doff aid was not very useful, and that it actually made doffing slightly more difficult because it forced the boots to sit at a right angle, making it harder to pull his feet out of the boots. Like subject 3 , he also felt that the step modified his hip angle and made it harder to get his glutes over the lip of the hatch ring. When doffing without the aid, subject 2 also noticed the 'Chinese finger trap' effect; however, he was able to use his right foot to hold his left boot in place while he pulled his foot out of the boot. Subject 5, who also completed three successful suit doffs, was similarly able to kick his feet loose from the boots.

Since the original doff aid had shown little to no utility over the first four test days, it was modified for subject 5's test day in an attempt to make it more useful. The modified doff aid consisted of a platform built on an incline, with the intention of creating a surface that the subject could brace his legs against while doffing the suit, or hook the legs over. The handle was extended to span the entire width of the doff aid, so that the subject could more easily manipulate the aid into the desired location. Additionally, two pegs were attached to the bottom of the doff aid, and four sets of oversized holes were drilled into the raised floor of the chamber, allowing the subject to drop the doff aid into a fixed set of holes so that it would remain fixed in place during doffing.

Subject 5 attempted to use the modified doff aid on one of his doffing attempts, but found it to be of minimal use. Rather than using a step or incline as a doffing aid, all of the test subjects commented that the doffing issues could likely be mitigated with some sort of foot restraint to hold the suit legs straight and the boots in place, such as a heel clip, toe bar or combination of the two. This was later implemented for the PFS pressurized testing.

In addition to rating their overall ability to doff the suit, subjects were also asked to use the Likert Acceptability Scale, a scale which ranks acceptability from ' 1 - Totally Acceptable' to '10 - Totally Unacceptable', to rate the location of the pull-up bar that was used to doff the suit. The pull-up bar was centered over the suit opening in the bulkhead and protruded approximately 4 in. into the vestibule, as pictured in Figure 22.

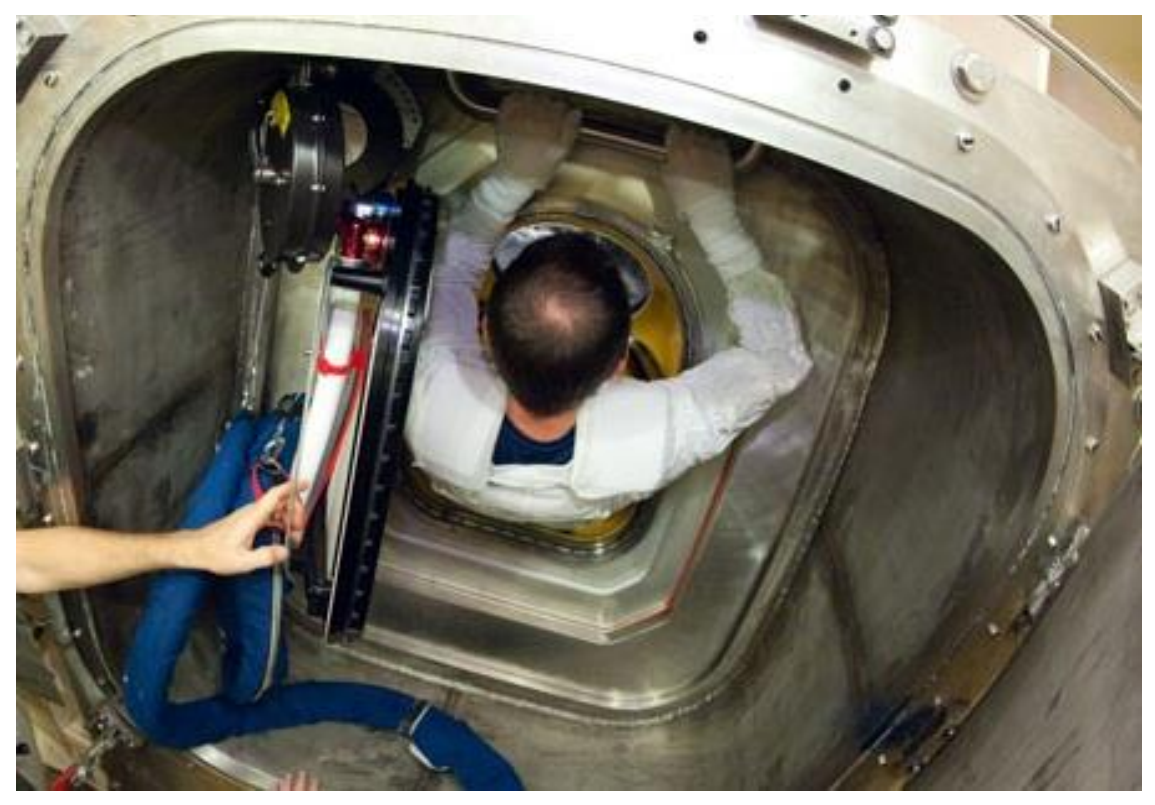

Figure 22 Pull-Up Bar Location

Both subjects who were able to doff the suit rated the pull-up bar as a ' 2 ', meaning that it was totally acceptable. Two of the test subjects also commented that it would be useful to have a second pull-up bar further back in the vestibule or some sort of dip bar in order to gain additional leverage desired for suit doffing

Due to the dip bar comment, foam blocks were added to the vestibule volume for the final test day to give the subject something to push against which would act like a dip bar. As shown in the doffing photo sequence (Figure 20), the subject used these blocks when doffing the suit. 


\section{Glove and Boot Adjustment}

One of the impacts of suitport operations on the suit design is that crewmembers must perform nominal suit adjustments, such as tightening their glove palm bar and boot instep, while pressurized. In an airlock, these operations would nominally be performed prior to suit pressurization. Without the ability to effectively tighten the palm bar on the gloves, mobility and glove fit during the EVA may be negatively impacted, and hand fatigue may increase. Similarly with the boots, lack of proper instep sizing may cause difficultly when walking in a gravity environment. Design of the Self Adjustable Phase VI gloves and Self Adjustable Rear Entry I-Suit (REI) boots was detailed in reference 2 .

Due to subject glove sizing and the limited sizes of Phase VI adjustable gloves that exist ( 2 sizes), only one of the five subjects wore and evaluated the self-adjustable gloves in his test. The subject who evaluated the gloves rated his ability to adjust them as a '2', or 'good - negligible deficiencies' on the Modified Cooper-Harper Scale, and preferred the t-handle mechanism over the 4-lobed mechanism due to the longer length the of knobs. He also commented that it would be nice to have additional knobs of this length on the adjustment mechanism.

All five subjects successfully completed the boot adjustment task at least one time during their test. Figure 23 from the dry runs displays a technique used to complete the boot adjustment task.

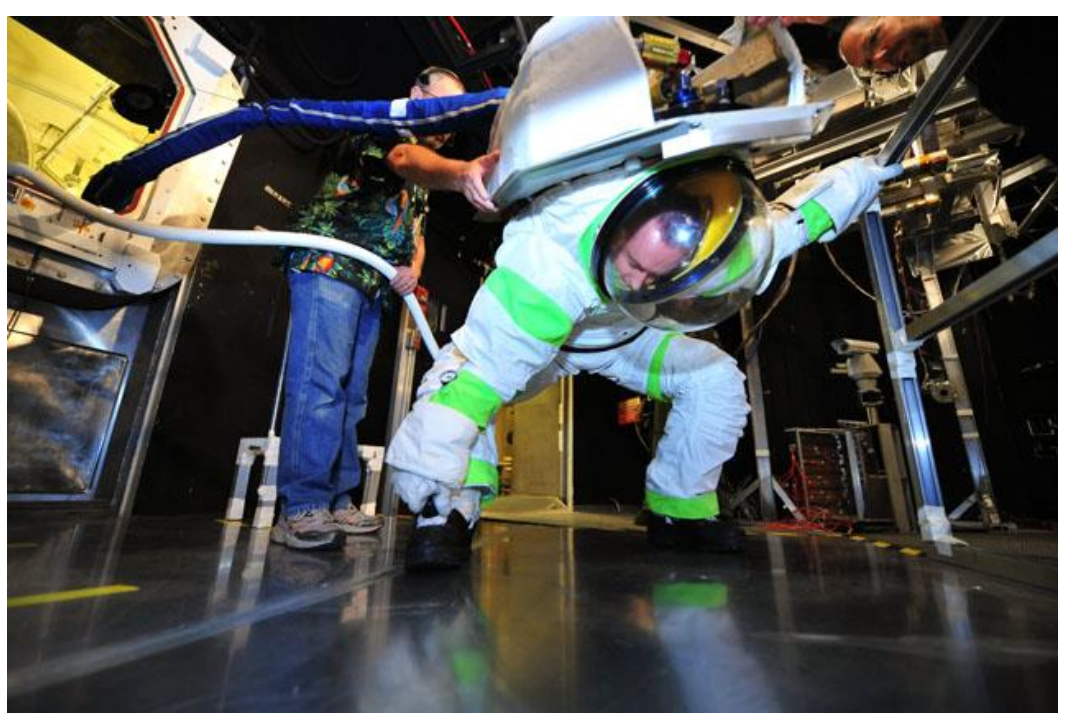

\section{Figure 23 Subject Gripping Handrail for Stability while Adjusting Right Boot}

As with the other tasks, subjects were asked to rate their ability to adjust their boots on the Modified CooperHarper Scale. Each subject's rating as well as the average rating for the boot adjustment task is provided in Figure 24. 


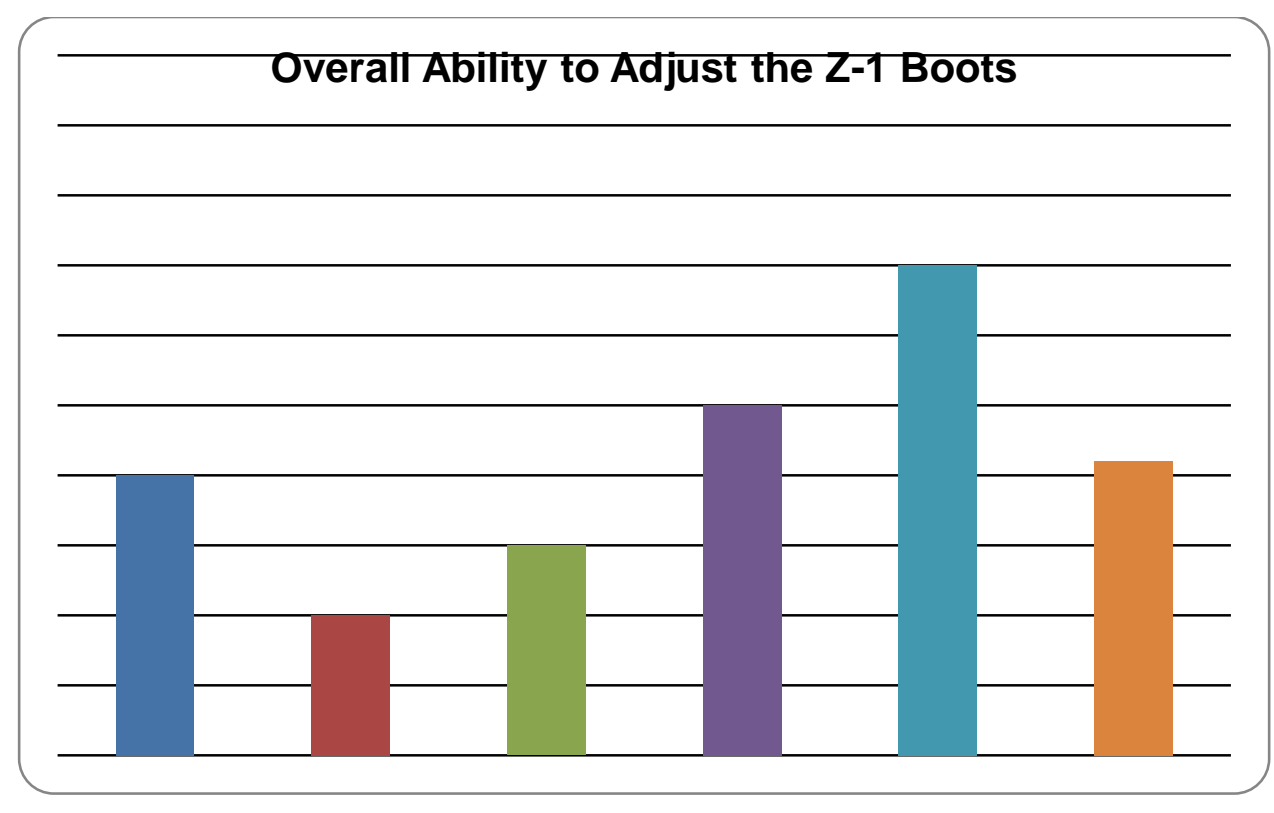

Figure 24 Boot Adjustment Ratings on the Modified Cooper-Harper Scale

As shown in Figure 5.2.2.3-6, the ratings varied from a '2', indicating 'good - negligible deficiencies' to a '7', indicating that the task had 'major deficiencies'. The larger range in this category is not completely surprising, as the ability to perform this task is well correlated to Z-1 familiarity and experience. The subjects who have spent the most time in the Z-1 Suit, and thus have practiced this task the most, gave the lowest, or best, ratings for this task, while the subjects who have less Z-1 Suit experience gave the highest, or worst ratings for this task. The average rating of just over a ' 4 ' indicates that the task had minor but annoying difficulties.

The subjects agreed that the suit provided adequate mobility to perform the task, and that reaching/accessing the $\mathrm{Boa}^{\mathrm{TM}}$ adjustment devices on the boots was not an issue. They also commented that the $\mathrm{Boa}^{\mathrm{TM}}$ mechanism itself was good, but that it required an excessive amount of turns to activate. The throw length of the mechanism is something that could be easily increased on a future iteration of the adjustable boots. A few subjects also commented that they received very little positive feedback to indicate that they were in fact actuating the mechanism. This lack of feedback was due to the fact that the Boas ${ }^{\mathrm{TM}}$ on the boots are an off-the-shelf device design for barehanded operations, and therefore have very small indentations on the adjustment knobs, which do not provide much feedback when operated with a pressurized, gloved hand. These knobs could easily be customized (as has been done with the glove adjustment mechanisms) to provide additional feedback when operated with a pressurized glove.

Overall, the Z-1 Suit and Marman Clamp Suitport Chamber B Test was very informative. Up until this test, pressurized suit donning and doffing had not been attempted and had been predicted to be relatively easy. The test results demonstrated that pressurized suit donning was manageable, but could be improved, while pressurized suit doffing in the tested suit/suitport/tool configuration was unacceptable.

\section{Pneumatic Flipper Suitport Testing}

The Z-1 Suit and Suitport testing consisted of a series of tests that spanned over one month performed at reduced pressure in Chamber B. The testing was split into two parts. The first part was performed with a blanking plate docked to the Pneumatic Flipper Suitport. This portion of the testing verified that the Pneumatic Flipper Suitport mechanism and structure could operate and withstand the 8.3 pressure differential without putting the test subjects or Z-1 suit at risk. The second part of testing was performed with a manned Z-1 Suit and the Pneumatic Flipper Suitport. This portion of the testing consisted of five different test subjects performing suitport operations 
including donning and doffing the pressurized Z-1 suit, and undocking from and docking to the suitport. Chamber B was pumped down to 6.4 psia while the manlock, back side of the suitport, and inside of the suit were exposed to ambient pressures thus creating the required 8.3 psid required for proving out the hardware.

The Space Suit and Crew Survival Systems Branch (EC5) along with the Systems Test Branch (EC4) conducted an unmanned reduced pressure test of the Pneumatic Flipper Suitport and a manned reduced pressure test of the Pneumatic Flipper Suitport and Z-1 Suit in Chamber B of the Johnson Space Center building 32. The unmanned testing started on September 5, 2012 and ended on September 7, 2012. The manned testing started September 18, 2012 and ended on September 28, 2012. The tests were to demonstrate operation of the Pneumatic Flipper Suitport and evaluate pressurized donning and doffing of a Z-1 Suit. The tests were completed with all test objectives either demonstrated or evaluated.

\section{Test Objective}

The test objectives for the Pneumatic Flipper Suitport testing were similar to the Marman clamp testing except that the manual override was planned to be used in the nominal testing. The simplicity of the override lent itself to being demonstrated in chamber. Additionally, a boot jack don doff aid was constructed and evaluated. The primary test objective from a suit perspective was to evaluate pressurized donning and doffing of the Z-1 space suit through a suitport. Secondary objectives included evaluating subjects' ability to adjust their own boots and gloves after donning and prior to doffing the pressurized suit, as well as their ability to dock and undock from the suitport at an 8.3 psi pressure differential.

\section{"Boot Jack" Foot Restraint}

The doffing aid from the Marman clamp testing was available for this test series. During the Marman Clamp Suitport Evaluation, test subjects overwhelmingly cited the need for a device to restrain the motion of the boots during donning and doffing and, if possible, keep the legs straighter. These comments subsequently drove the design of the boot jack used in the Pneumatic Flipper Suitport (PFS) evaluation. The "boot jack" foot restraint is a preliminary prototype concept intended to assist test subjects in the pressurized don/doffing of a space suit. This aid restrains the boots, and thereby the suit legs as well, keeping them from rotating out of the nominal position when donning, and straightens the legs of the SSA Lower Torso Assembly (LTA) to provide a more open path (i.e. less bend in knee and ankle) for test subject's feet/legs to pass through the legs of the LTA down to the boots during donning. It was also felt that this foot restraint would aid in the doffing of a pressurized space suit by providing the test subject some form of leverage to act against when exiting the suit.

The boot jack, shown in Figures 25 and 26, was fabricated using the boot plate from an Neutral Buoyancy Laboratory (NBL) Extravehicular Mobility Unit (EMU) Portable Foot Restraint (PFR) that was modified to increase the height of the toe bar and provide a means to horizontally adjust the toe bar. The traditional EMU boot heel clip was removed and a cowboy boot like boot jack was added to the aft end of the boot plate to prevent the boot heel from coming out of the restraint when the suit is at operating pressure. A handle was added to allow the test subjects to move the foot restraint in and out of position. Tapered posts were installed below the forward boot plate spacers to allow gross alignment with the positioning holes in the floor. A notch was cut into the rear of the post so the posts engaged the test area floor when the suit is pressurized due to the column pressure in the legs. 


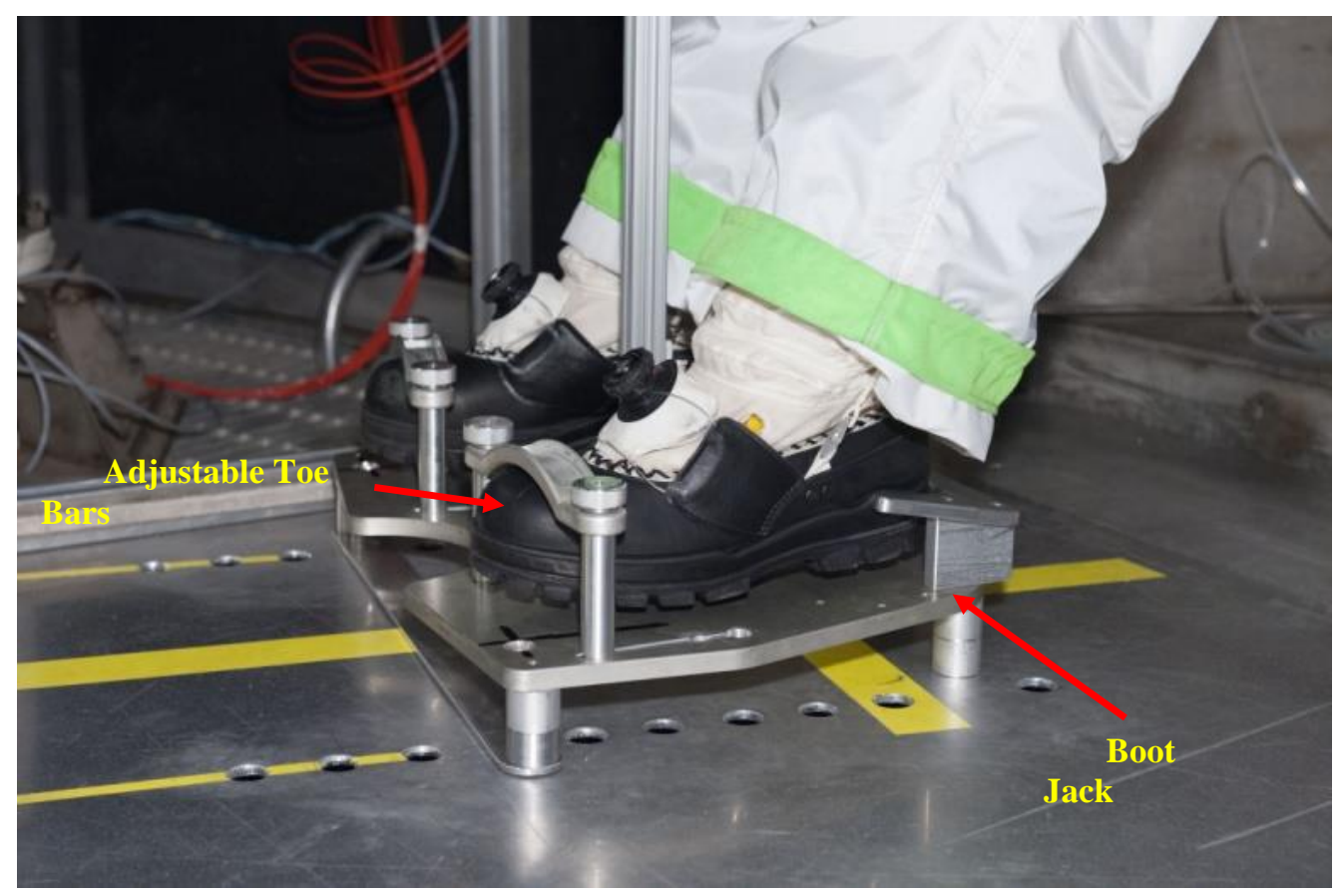

Figure 25 "Boot Jack” Foot Restraint

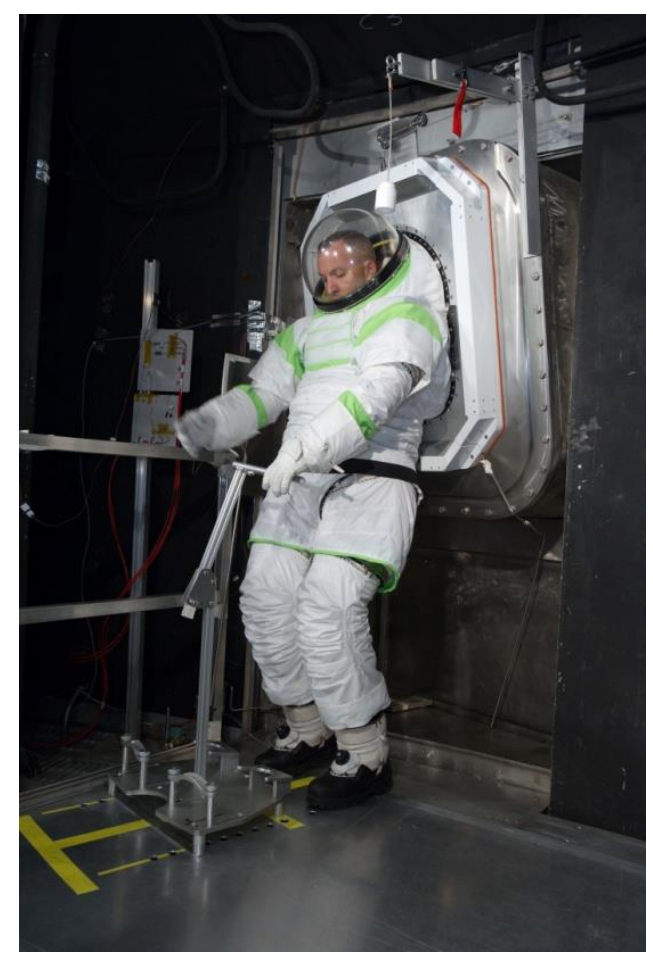

Figure 26 Doffing Aids 


\section{Pneumatic Flipper Suitport Manned Test}

\section{Donning}

The first step for performing the Z-1 suit tasks was to don the suit that was secured to the Suitport. The test subjects did not have any comments concerning suitport affecting the donning of the Z-1 suit. This testing marked the second series of pressurized donnings of a space suit. Unlike the Marman clamp Suitport testing; all test subjects were able to perform multiple pressurized suit donnings.

Upon completing donning, subjects were asked to rate their overall ability to don the suit using the Modified Cooper-Harper Scale. The subjects' ratings for their ability to don the pressurized Z-1 suit with the boot jack installed are provided below (Figure 27).

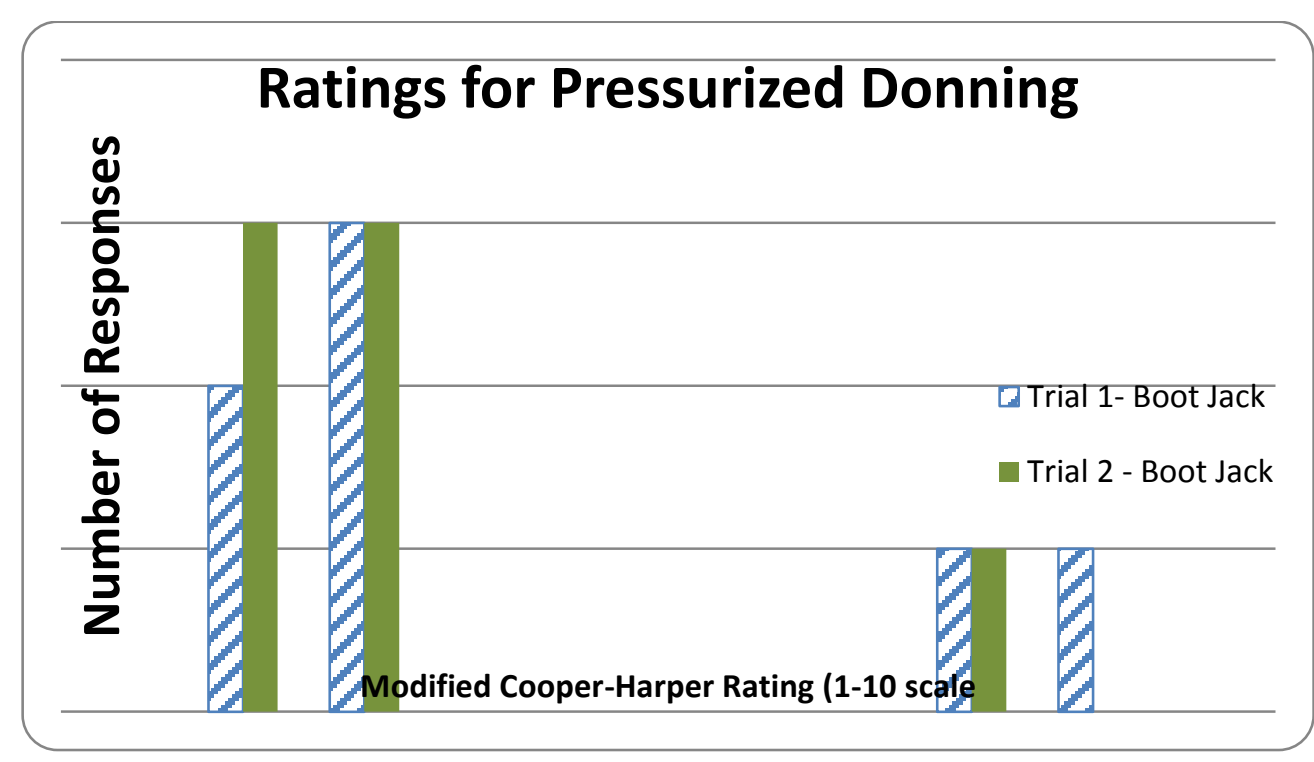

Figure 27 Suit donning ratings on the Modified Cooper-Harper Scale

The majority of the subjects' ratings for donning ranged from 4 (minor but annoying difficulty) to 2 (good negligible deficiencies). Two subjects' ratings were significantly higher, ranging from 8 (major deficiencies; max operator compensation needed) to 9 (major deficiencies; intense operator compensation needed). Determination of why these subjects had significantly more trouble donning the pressurized Z-1 suit compared to the rest of the subjects is still in work. Possible hypotheses for these difficulties are test subject strength and fit issues or suit positioning relative to the test floor (i.e. floor was not low enough which caused the suit's legs to have a bend instead of being able to be placed in a straight position.)

Two subjects tried a third suit donning with no aid (i.e. no foot restraint or step aid). Both subjects' ratings for their ability to don the suit significantly increased. The first subject went from an average rating of 3 (fair- some mildly unpleasant deficiencies) to 6 (very objectionable difficulty) and the second subject went from an average rating of 2 (good - negligible deficiencies) to 5 (moderately objectionable difficulty). The increase in difficulty in donning without an aid was an expected outcome because of the results of the Marman clamp suitport testing where it was recommended that a pressurized suit don/doff aid be developed to help restrain and try to straighten the suit legs to open up a larger donning path through the LTA.

Different techniques/aids were utilized to try and alleviate the interference points in the suit legs and ankles during donning. All subjects used the boot jack foot restraint for their initial donning of the suit, one subject attempted a subsequent donning with an angled step aid, and two other subjects tried subsequent donnings with no aid and their legs free. Figure 28 shows the boot jack and Figure 29 shows the angled step aid used for donning. 


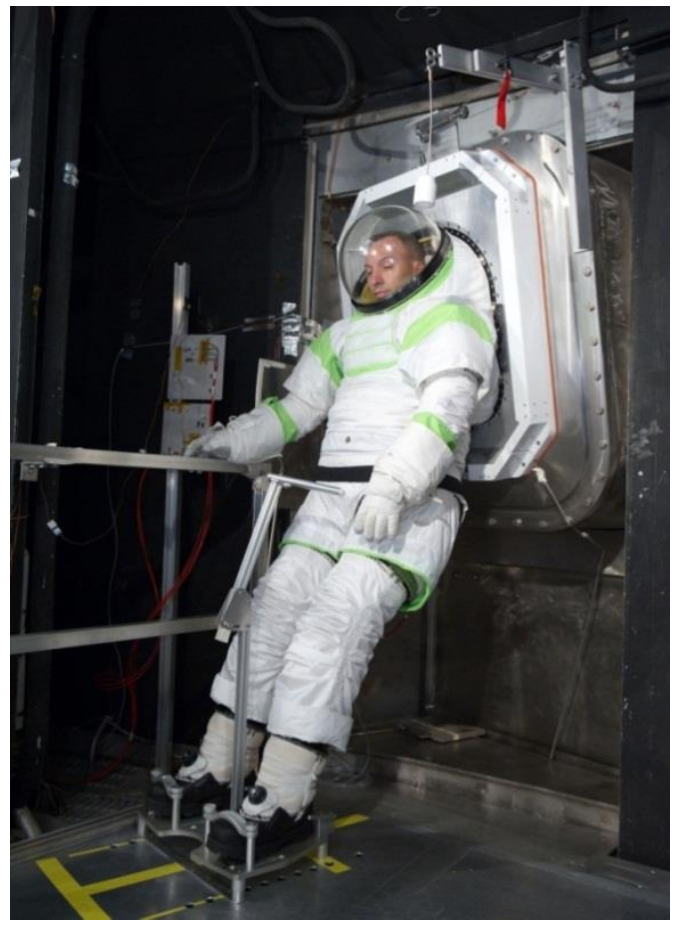

\section{Figure 28 "Boot Jack" Foot Restraint}

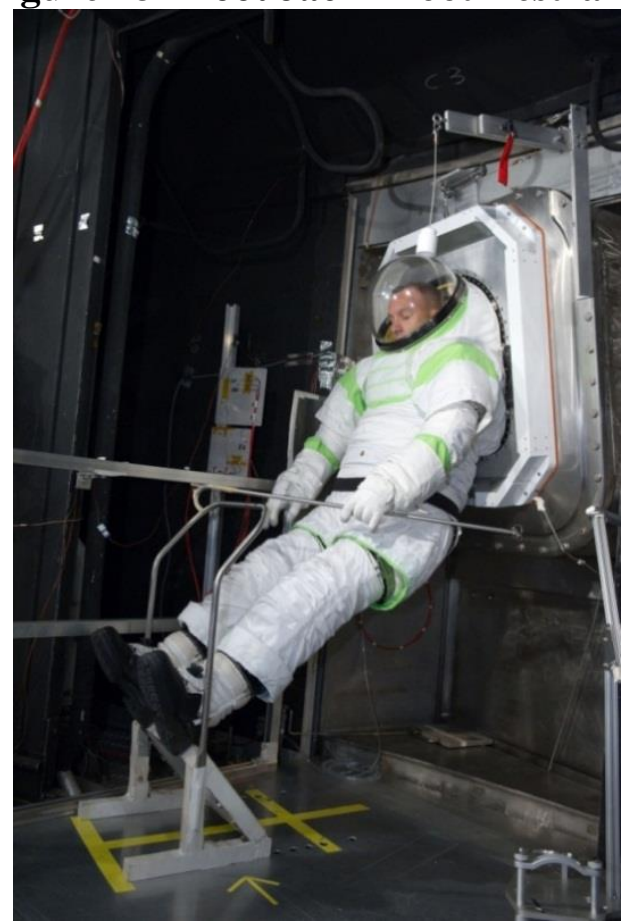

Figure 29 Angled Step Aid

Of the 8 subjects that used the boot jack, 6 felt this aid helped by straightening out the suit legs which opened a path for donning and it secured the legs/feet in place preventing flailing so they could slide in relatively easily. Of the 2 remaining subjects one felt the boot jack didn't provide any significant advantage from their pervious Marman Clamp Suitport evaluation where no foot restraint was used. The other remaining subject felt the foot restraint was 
no help at all, and that it could possibly have hindered their donning. This last subject also tried donning with the angled step aid and it was believed by them that this aid allowed the leg ingress to be more controlled.

\section{Undocking}

Pneumatic System

The first system used for undocking test subjects from the suitport is the pneumatic system. The test subjects all provided scores of 1 or 2 (Totally Acceptable, no improvements necessary) on the Likert Acceptability Scale as related to the time involved in the pneumatic system opening the flippers.

After the release of the flippers, the test subjects attempted to undock from the suitport. The majority of the test subjects had problems with the first or second undocking. The range of scores for the undocking using the pneumatic system is from 2 to 6 (Good to Very Objectionable Difficulty) on the Modified Cooper-Harper Scale. The scores tended to decrease (improve) as the number of undocks for the test subject increased. The subjects indicated that the undock is technique dependent but that once the body posture for undocking had been learned undocking is easy. For instance, the test team observed that some subjects were attempting to use a technique learned during the Marman suitport testing where they leaned forward to release the top of the SIP from the suitport before straightening up and stepping away from the suitport. This technique did not translate to the PFS undocking because the Portable Life Support System (PLSS) mockup shape for this test was not as tapered as the one used on the Marman test and the PLSS mockup would catch on the top edge of the PFS. As the subjects practiced undocking, they quickly learned better techniques for this suitport design. In some cases, the test subjects would be caught on the bottom flipper during undocking but would push the SIP against the suitport to disengage the SIP from the flippers.

All of the test subjects used visual and/or audio cues from the flipper as an indication that they can undock from the suitport with 4 out of 5 stating that they heard the flipper mechanism click when they are able to undock.

\section{Mechanical System}

The second system used for undocking test subjects from the suitport is the mechanical system. During the test, at the request of the Suitport Project Manager, the test setup was modified to reduce the manual force required to actuate the flippers. The trade off in having a lower force for flipper actuation is a longer travel of the test facility mechanism that is connected to the flipper mechanical system. Test subjects 1,2, and 5 used a high force, approximately $22 \mathrm{lb}$, and short travel mechanical release while test subjects 3 and 4 used a low force, approximately $11 \mathrm{lb}$, and long travel mechanical release.

For the test subjects that used the high force and short travel mechanical release, the range of scores for undocking using the mechanical system is from 2 to 5 (Good to Moderately Objectionable Difficulty) on the Modified Cooper Harper Scale. Two of the three test subjects did not have any problems with the force. The comments from the subjects focused on the need to push on the SIP to allow undocking and the need for an indicator that the flippers have disengaged.

For the test subjects that used the low force and long travel mechanical release, the range of scores for undocking using the mechanical system is from 4 to 5 (Minor but Annoying Difficulty to Moderately Objectional Difficulty) on the Modified Cooper Harper Scale. Both test subjects indicated that the travel required for releasing the flippers are too long for the range of motion available while inside the suit. Both of the test subjects also commented on the need to push on the SIP to allow undocking.

\section{Docking}

The test subjects docked to the suitport after performing pressurized operations as part of the test procedures. The test team asked about alignment using the PLSS and flippers and the docking process. The first question asked was about the alignment of the PLSS and using the flipper for docking. The test subjects gave scores on the Modified Cooper Harper Scale between 8 and 3 (Major Deficiencies to Fair) for the first run and revised the scores towards the 4 to 2 (Minor but Annoying Difficulty to Good) range as they performed more dockings. The test subjects did not have any direct comments about using the PLSS for alignment. Two of the subjects did indicate that they would prefer longer flippers or the addition of a $\mathrm{V}$ guide for alignment. 
For the docking process, the initial scores ranged from 5 to 2 (Moderately Objectionable to Good). Again, just as with undocking, some subjects started with the same technique learned for the Marman suitport testing but quickly found that it was not applicable to this design and experimented until they had figured out a better technique. As the test subjects developed their own docking technique, the scores ranged from 4 to 2 (Minor but Annoying Difficulty to Good). The test subjects indicated that docking is technique dependent and that training is needed. A test subject indicated that a handrail helped him maintain control during docking. It is believed that a minor modification to the PLSS shape, increased taper at the top, would significantly reduce the docking learning curve.

\section{Doffing}

The last step is doffing from the Z-1 suit. The suitport test team incorporated the comments from the Marman Clamp Suitport test and had an additional handle bar installed for doffing. In addition, foam pads were placed in the vestibule to act as a substitute for the dip bar that exists in the Marman Clamp Suitport design.

Doffing the pressurized suit proved to be more difficult than donning. Unlike the Marman clamp Suitport testing, all test subjects were able to perform multiple pressurized suit doffings.

As with suit donning, subjects were asked to rate their overall ability to doff the suit using the Modified CooperHarper Scale. Each subject's rating as well as the average rating for the doffing task are provided in Figure 30. The data is divided by subject's donning attempts; the trial description indicates when the boot jack was used. The description 'alt concept' refers to the use of the step aid from Marman testing or no aid at all.

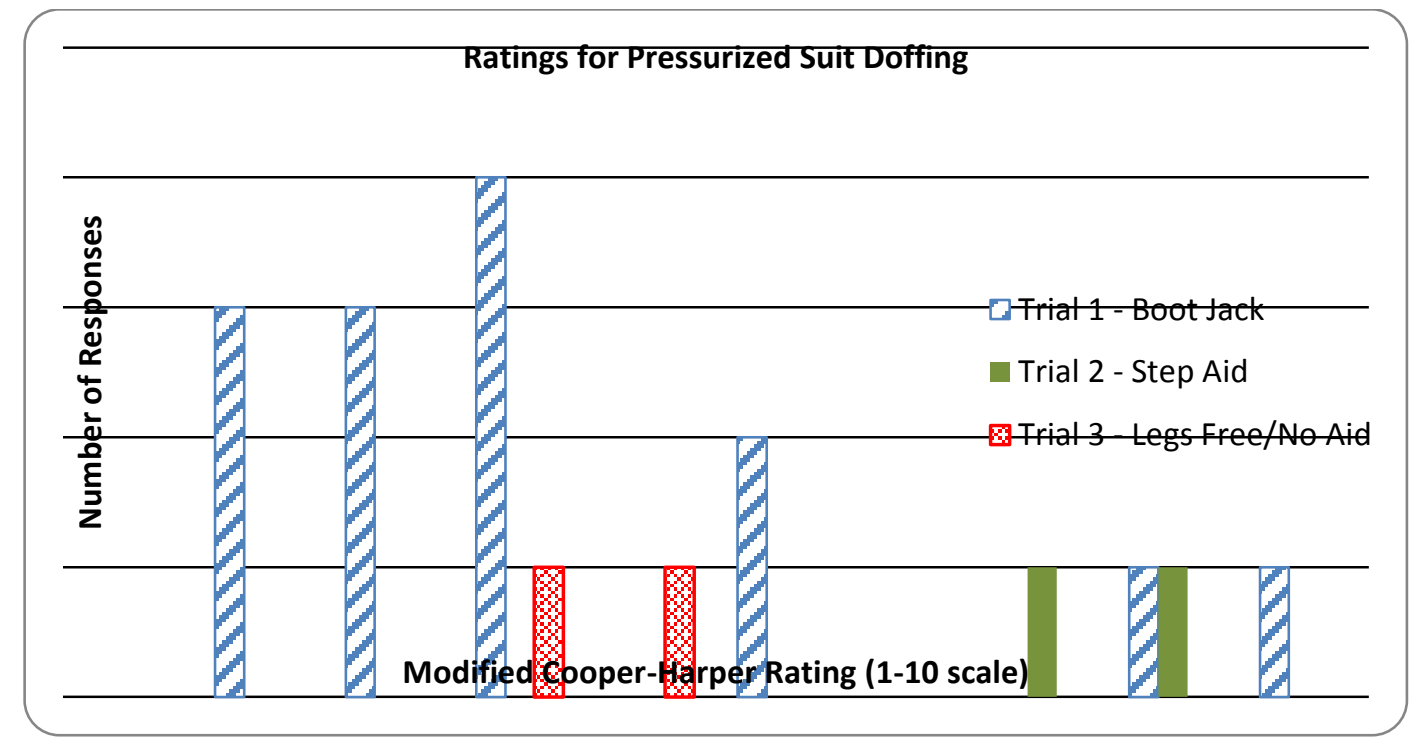

Figure 30 Suit doffing ratings on the Modified Cooper-Harper Scale

The majority of the subjects' ratings for doffing with the boot jack ranged from 6 (very objectionable difficulty) to 2 (good - negligible deficiencies). The ratings of two subjects were noticeably higher with the boot jack, ranging from 8 (major deficiencies; max operator compensation needed) to 10 (major deficiencies; unable to perform task); both of these subjects elected to attempt their second doff trial using an alternate concept (step aid). Even with the swap of aids, both subjects rated doffing the suit to have 'major deficiencies.' The cause for the increased difficulty experienced by these two subjects, as compared to the other six, is not clear.

Base on the data collected from the evaluations, the ability of the majority of test subjects to don/doff a pressurized suit were comparable, but from observation doffing of the Z-1 suit seemed slightly more difficult than donning. Two subjects encountered interference points in the ankle area and one subject encountered interference at 
the back of the knee, both most likely due to bladder folds, which obstructed the removal of their feet. Also, three of the subjects found the Liquid Cooling Garment (LCG) cooling lines getting caught up in the waist region. Once they pulled the LCG lines up over the waist of the suit, this issue was alleviated. Another item of note is that two subjects commented on the lower edge of the suit hatch opening. This edge was either an interference point, possibly due to the LCVG cooling lines getting caught on the edge, or the edge had a sharp angle which made doffing uncomfortable as they reached back for the pull-up bar or blue foam.

\section{Doffing Aids}

All subjects used the boot jack foot restraint for their initial doffing of the suit, two subjects attempted a subsequent doffings with an angled step aid, and two other subjects tried subsequent doffings with no aid and their legs free.

The boot jack helped to hold the suit legs straighter and reduce the bend in the knees to provide a clearer donning path in the legs. The Angled Step Aid was used more for leverage to raise the subject in the suit to so they could free their arms to be able to reach the pull-up bars and the blue foam. The subjects' ratings of the effectiveness of the boot jack foot restraint as a doffing aid are provided below (Figure 31), as well as an overall average rating.

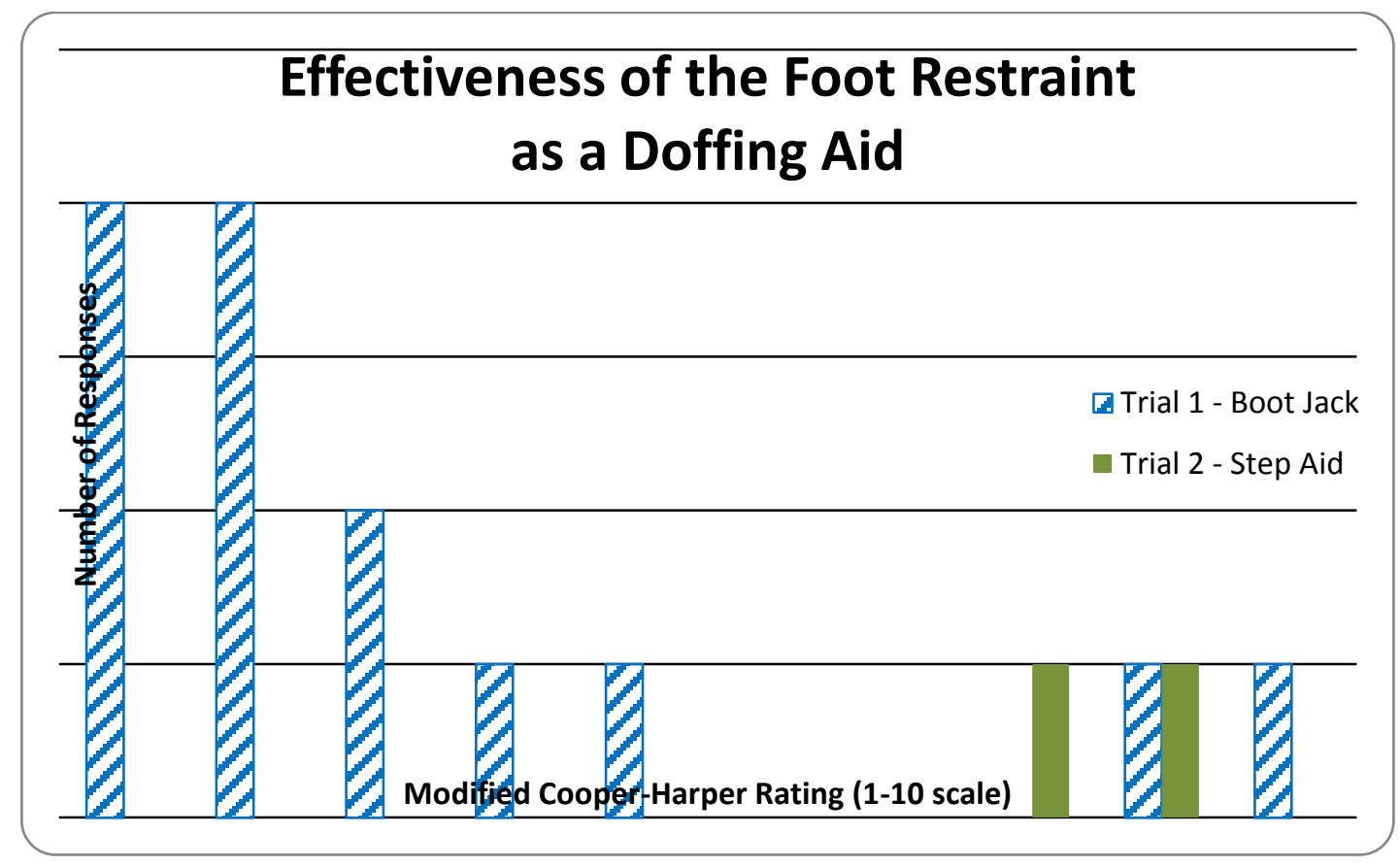

\section{Figure 31 Effectiveness of Boot Jack foot restraint during pressurized suit doffing; ratings on the Modified Cooper-Harper Scale}

The ratings again fell in pattern similar as the ability to don ratings. The majority of the subjects' ratings for donning ranged from 5 (moderately objectionable difficulty) to 1 (excellent - highly desirable) with the average rating being 4 (minor but annoying difficulty). Subjects' 2 and 4 ratings were significantly higher, ranging from 8 (major deficiencies; max operator compensation needed) to 10 (major deficiencies; unable to perform task).

Some comments concerning the foot restraint were that majority of the subjects felt it helped with doffing because it held the suit legs steady and in place, but that it also made it hard to get leverage with their feet when their legs were restrained. One subject noted that was easier to get their shoulders out without boot jack and another subject stated without foot restraint it was initially easier to point toes and slide out feet not being restrained. 


\section{Conclusion}

\section{Pneumatic Flipper Suitport}

The planned objectives for Pneumatic Flipper Suitport testing were completed. There are areas that need to be examined in the next suitport design based on the comments documented in section 5 of the test report. Specifically, the addition of an indicator or indicators that the flippers are in the dock versus undock position. Modification of the flippers to aid in alignment during docking or addition of an alignment guide. While not part of the recommendation by the test subjects, the PLSS geometry might need to be revisited. As noted earlier, many of the test subjects had a tendency to pivot on the bottom edge of the Pneumatic Flipper Suitport while undocking. Due to the taller/longer sidewalls of the PLSS, the test subject could not undock with the suitport due to the PLSS top surface hitting the suitport outer frame. An alternative to changing the PLSS geometry is to train potential future crew members on the proper technique for undocking.

The results from the manned Pneumatic Flipper Suitport test will be incorporated into future suitport designs.

\section{Z-1 Suit}

Overall, the Z-1 Suit and Pneumatic Flipper Suitport Chamber B Testing was successful given that all subjects were able to don and doff the pressurized Z-1 suit at least once. These test results demonstrated that pressurized suit donning and doffing are manageable, but can be improved, especially doffing, as some subjects had to use maximum effort to doff the suit.

The results of the Pneumatic Flipper Test indicate that the greatest challenges for both donning and doffing are: 1) maintaining a clear path from the hips to the boots, and 2) providing a means for the subject to get leverage in the suit so they can raise themselves up in the suit to free their arms/shoulders to allow their upper body to assist with the doffing task. The clear path can generally be achieved with the suit legs straight and slightly out in front of the suit with the boots fixed in a forward facing position, but it is currently unknown if reduced gravity environments will further complicate the pressurized donning process as most subjects used their own weight to help them slide down into the suit. The ability to gain leverage to raise one's self in the suit to free their arms can be obtained by either climbing up the bladder of the legs or by stepping up on one of the donning aids, but this can generally leave one's legs free and not secured which can increase the difficulty of doffing. It is believed that a reduced gravity environment will only aid in the doffing process. It is assumed a subject would be able to float freely up in the suit allowing them to more easily free their arms and extract themselves from the suit as there would be less than 1-g acting on a person's mass.

The glove and boot adjustment tasks were found to be acceptable. Minor improvements to the adjustment mechanisms, such as modifying the mechanism knob design and increasing the throw length of the mechanisms so that fewer rotations are required to make adjustments, could make these tasks slightly better. While some subjects had issues managing the weight and center of gravity of the suit during the boot adjustment task, these issues will likely be mitigated when working in a reduced gravity environment. The suit itself provided adequate mobility to perform the task.

Based on the variety of test subject comments and team observations, it is not completely clear why some subjects were more successful than others. It is likely due to the combination of subject leg/foot anthropometry, suit geometry, and technique, but it is currently hypothesized larger feet and less flexible ankles are a hindrance when performing a pressurized don of a space suit due to the inherent non-flexibility of a pressurized suit.

Finally, it was observed that as subjects got more repetitions/training don/doffing the suit, the easier these tasks seemed to become. Development of some kind of less expensive and rapidly repeatable method of conducting suited manned pressurized don/doffing evaluations in the laboratory environment, similar to glovebox testing, would be extremely advantageous. This would allow for the continuous testing of multiple don/doff techniques/aids to refine these concepts. Also, if designed to also interface with the reduced gravity planes this don/doff test bed could be tested in reduced gravity environments to evaluate the extent of gravity's effects on pressurized suit don/doffing as well as to determine any new issues introduced by reduced gravity environments that are not currently apparent from the testing done to date. 
Looking further down the road at the Z-2 suit design and beyond, it is likely possible to mitigate the issues seen during testing through a combination of suit, suitport interface, and don/doff aid design modifications.

Extravehicular Activity Unit (EMU)-like modular sizing could easily mitigate any issues with excess bladder folds. And stops on the ankle bearings could keep the boots facing forwards during donning while still allowing for adequate ankle mobility. Even with these suit modifications, some type of don/doff aid may be necessary to provide a stable platform against which to react. It is hypothesized that changes to the suitport angle (tilted more toward the horizontal) and relative placement of the overhead pull-up bar could also minimize some of the challenges associated with suit doffing.

\section{Summary}

This paper has re-examined the design of the Marman Clamp Suitport, the Z-1 Suit and the plans to test them in the NASA JSC Chamber B. This paper introduced a new suitport design, the Pneumatic Flipper Suitport. Test results from testing on the MMSEV aft cabin with the Marman Clamp Suitport are reported. Then test results from two series of chamber tests, the first human pressurized don doffs ever with a spacesuit and both suitport designs are documented. Subject ratings of most tasks are presented. This design test effort has significantly improved the technology readiness level of the suitport, taking it from the concept stage, to a demonstrated prototype in ground testing. The next step, when funding and appropriate missions are identified is to implement suitport in a human vacuum chamber test with the chamber at space vacuum conditions, followed by thermal vacuum testing with a prototype spacesuit and life support system. 